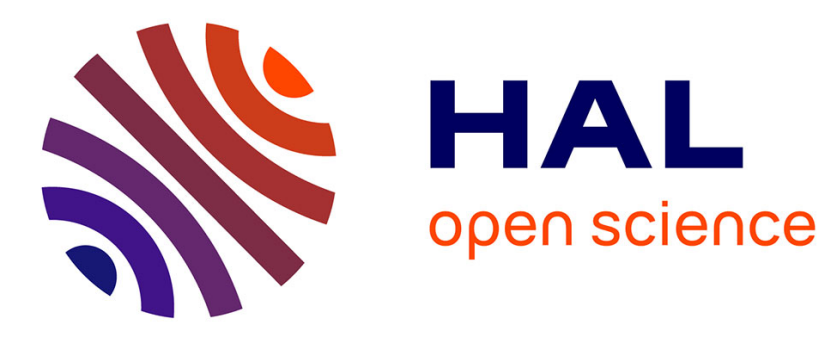

\title{
Quantification of biomarkers for beef meat qualities using a combination of Parallel Reaction Monitoring- and antibody-based proteomics
}

\author{
Muriel Bonnet, Julien Soulat, Joanna Bons, Stéphanie Léger, Leanne de
} Koning, Christine Carapito, Brigitte Picard

\section{To cite this version:}

Muriel Bonnet, Julien Soulat, Joanna Bons, Stéphanie Léger, Leanne de Koning, et al.. Quantification of biomarkers for beef meat qualities using a combination of Parallel Reaction Monitoring- and antibody-based proteomics. Food Chemistry, 2020, 317, pp.126376. 10.1016/j.foodchem.2020.126376 . hal-02494286

\section{HAL Id: hal-02494286 https://hal.science/hal-02494286}

Submitted on 9 Oct 2020

HAL is a multi-disciplinary open access archive for the deposit and dissemination of scientific research documents, whether they are published or not. The documents may come from teaching and research institutions in France or abroad, or from public or private research centers.
L'archive ouverte pluridisciplinaire HAL, est destinée au dépôt et à la diffusion de documents scientifiques de niveau recherche, publiés ou non, émanant des établissements d'enseignement et de recherche français ou étrangers, des laboratoires publics ou privés. 
1 Quantification of biomarkers for beef meat qualities using a combination of parallel

2 reaction monitoring- and antibody-based proteomics

3 Muriel BONNET ${ }^{\mathrm{a}, *}$, Julien SOULAT $^{\mathrm{a}}$, Joanna BONS ${ }^{\mathrm{b}}$, Stéphanie LÉGER ${ }^{\mathrm{c}, \mathrm{d}}$, Leanne DE

$4 \quad$ KONING $^{\mathrm{e}}$, Christine CARAPITO ${ }^{\mathrm{b}}$, Brigitte PICARD ${ }^{\mathrm{a}}$

5 a INRAE, Université Clermont Auvergne, Vetagro Sup, UMRH, 63122, Saint-Genès-

6 Champanelle, France

7 b Laboratoire de Spectrométrie de Masse BioOrganique (LSMBO), IPHC UMR 7178, CNRS,

8 Université de Strasbourg, 67000 Strasbourg, France.

$9{ }^{\mathrm{c}}$ Université de Clermont Auvergne, Université Blaise Pascal, Laboratoire de Mathématiques, BP 10448 F-63000 Clermont-Ferrand, France

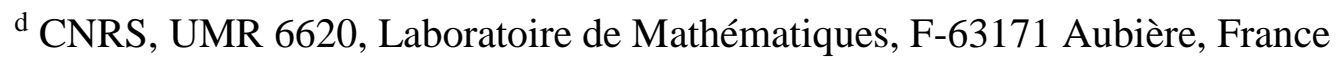

${ }^{\mathrm{e}}$ Institut Curie centre de recherche, Université de recherche PSL Plateforme RPPA, 26 rue de

13 l’Ulm, 75248 Paris, France

BONNET Muriel: $\underline{\text { muriel.bonnet@inrae.fr }}$

SOULAT Julien: julien.soulat@inrae.fr

BONS Joanna: joanna.bons@etu.unistra.fr

DE KONING Leanne: leanne.de-koning@ curie.fr

CARAPITO Christine: ccarapito@unistra.fr 
PICARD Brigitte: brigitte.picard@inrae.fr

Corresponding author: Muriel BONNET

UMRH Herbivores, Clermont-Auvergne-Rhône-Alpes, 63122 Saint-Genes-Champanelle, France

$\underline{\text { muriel.bonnet@inrae.fr }}$

Tel. +33 (0) 473624701

\section{ABSTRACT}

We and others have identified biomarker candidates of tenderness or marbling, two major attributes of bovine meat-eating qualities for consumers' satisfaction. In this study, reverse phase protein arrays (RPPA) and targeted mass spectrometry assays using parallel reaction monitoring (PRM) were developed to test whether 10 proteins pass the sequential qualification and verification steps of the challenging biomarker discovery pipeline. At least MYH1, TPI1, ALDH1A1 and CRYAB were qualified by RPPA or PRM as being differentially abundant according to marbling values of longissimus thoracis and semimembranosus muscles. Significant mathematical relationships between the individual abundance of each of the four proteins and marbling values were verified by linear or logistic regressions. Four proteins, TNNT1, MDH1, PRDX6 and ENO3 were qualified and verified for tenderness, and the abundance of MDH1 explained $49 \%$ of the tenderness variability. The present PRM and RPPA results pave the way for development of useful meat industrial multiplex-proteins assays. 
Keywords: Proteins, Tenderness, Marbling, Reverse Phase Protein Array, Quantitative Mass Spectrometry, Targeted Proteomics

\section{Introduction}

The intramuscular adipose tissue, also called marbling, and tenderness are major attributes that determine the meat-eating qualities of beef and contribute to the economic value of carcasses and meat. For example, the grading of carcasses in North America is influenced by the amount of marbling within certain limits, the more marbling the higher the grade. Tenderness is a top priority quality attribute that most eating quality systems focus on, because it is a primary consideration in consumer satisfaction. The control of both tenderness and marbling is thus a major concern for the beef sector, with the challenge of producing tender and flavoursome beef. The gold standards for tenderness evaluation are the Warner Bratzler Shear Force or the sensory panel evaluation, and marbling is assayed by the chemical analysis of intramuscular lipid content. Because these gold standards have significant drawbacks, such as the time of analysis and the important amount of meat required for analyses, investigations of higher throughput instrumental methods have been carried out to manage and predict beef-eating quality. Several technologies such as tomography, ultrasound and visible-near infrared spectroscopy have been developed to evaluate beef tenderness and marbling, mainly on carcasses or muscle/meat as recently reviewed (Farmer \& Farrell, 2018). Few quantitative proteomics methods (Wu, Dai, \& Bendixen, 2019) begins to exploit the hundreds of markers of tenderness (Picard, Gagaoua, \& Hollung, 2017) and marbling (Baik et al., 2017; Ceciliani, Lecchi, Bazile, \& Bonnet, 2018) deciphered by high throughput transcriptomic and proteomic assays in a perspective to develop methods usable on dead and alive animals. Yet, molecular markers, as well as pipelines for biomarkers discovery and validation, were developed (Drabovich, Martinez-Morillo, \& Diamandis, 2015; Rifai, Gillette, 
targeted therapies. We hypothesize that biomarkers of tenderness or marbling could be used to manage and predict these beef-eating qualities. To date, proteomics assays comparing meat samples differing exclusively with respect to marbling or tenderness have revealed hundreds of candidate protein biomarkers of tenderness (Picard, Gagaoua, \& Hollung, 2017) and marbling (Baik et al., 2017; Ceciliani et al., 2018; Thornton, Chapalamadugu, Eldredge, \& Murdoch, 2017). However, they were not pursued to the next phases of "qualification" and "verification" of the biomarker discovery pipeline. "Qualification" requires demonstration that the differential abundance of a candidate biomarker observed in discovery is seen using alternative, targeted methods. "Verification" is the extension to a larger number of samples that closely represent the population in which a final test would be deployed (Rifai et al., 2006). A requisite to conduct these phases of "qualification" and "verification" is the development of quantitative methods for candidate biomarkers of marbling and tenderness, and the selection of biological materials/samples. Among the quantitative methods that are investigated here (Meyer \& Schilling, 2017; Solier \& Langen, 2014; Vidova \& Spacil, 2017), Reverse Phase Protein Array (RPPA) was presented by (Akbani et al., 2014) as a "miniaturized antigen-down or dot-blot immunoassay suitable for quantifying the relative, semi-quantitative or quantitative abundance of protein". Because of its multiplex capability, RPPA allows the identification of tens of candidate biomarkers on a few hundreds of samples. Another powerful antibody-free approach for the absolute quantification of proteins is targeted proteomics coupled to isotope dilution. Among the panel of targeted proteomics methods, parallel reaction monitoring (PRM) (Gallien et al., 2012; Peterson, Russell, Bailey, Westphall, \& Coon, 2012), performed on high-resolution/accurate-mass instruments, offers high sensitivity and specificity, while covering a high dynamic range (Borràs \& Sabidó, 2017; Bourmaud, Gallien, \& Domon, 2016; Shi et al., 2016). 
The objective of the present study is thus to test the hypothesis that analytical performances of PRM and RPPA would be suitable for "qualification" and "verification" phases to prioritize candidate biomarkers. Therefore, we focused on ten muscular proteins previously identified as candidate biomarkers of meat marbling or tenderness, and further demonstrated the complementarity of PRM and RPPA assays.

\section{Materials and Methods}

All chemicals described in this section were purchased from Sigma-Aldrich (St Quentin Fallavier, France) when the company is not specified.

\subsection{Description of animals and muscles}

In order to produce the biological material required for the "qualification" and “evaluation” phases of the biomarker discovery pipeline, 43 muscles from 35 Rouge des Prés cows $(n=30$, mean slaughter age 63 months) and steers $(n=5$, mean slaughter age 33 months) were used as a subset of previously described samples (Picard, Gagaoua, Al Jammas, \& Bonnet, 2019). Rouge des Prés breed was chosen as a meat and dairy breed, and cows are reared for meat production and consumption (60\% of consumed bovine meat) in France. All animal trials described herein were conducted according to relevant international guidelines (European Union procedures on animal experimentation - Directive 2010/63/EU) for the use of production animals in animal experimentation. The 43 samples consisted of 23 samples of semimembranosus (SM) and of 20 samples of longissimus thoracis (LT) muscles chosen for their good representativeness of the biological variation of marbling and tenderness. Indeed, the values of marbling, described by the IMF (Intra Muscular Fat) content, assayed according to the Soxhlet method described in (Couvreur, Le Bec, Micol, \& Picard, 2019), ranged from 0.45 to $8.38 \%$ of fresh muscle with means of 4.04 and $4.39 \%$ for SM and LT muscles. The 
value of Warner-Bratzler shear force assayed as described in (Couvreur, Le Bec, Micol, \& Picard, 2019) ranged from 23.63 to $76.91 \mathrm{~N} / \mathrm{cm}^{2}$ with means of 47.73 and $31.40 \mathrm{~N} / \mathrm{cm}^{2}$ for SM and LT muscles (Supplementary Table 1).

\subsection{Protein extraction}

Proteins were extracted from frozen muscle samples by homogenizing the samples in the "Precellys 24" tissue homogenizer (Bertin technologies, Saint Quentin-en-Yvelines, France). Briefly, around $80 \mathrm{mg}$ of frozen muscle for each animal was grinded using $1.4 \mathrm{~mm}$ ceramic beads in a buffer containing $50 \mathrm{mM}$ Tris (pH 6.8), 2\% SDS, 5\% glycerol, $2 \mathrm{mM}$ DTT, 2.5 mM EDTA, 2.5 mM EGTA, 1x HALT Phosphatase inhibitor (Perbio Science, Villebon-surYvette, France), Protease inhibitor cocktail complete MINI EDTA-free (Roche, Meylan Cedex France, 1 tablet/10 mL), $2 \mathrm{mM} \mathrm{Na} 3 \mathrm{VO} 4$ and $10 \mathrm{mM} \mathrm{NaF}$. The extracts were then boiled for $10 \mathrm{~min}$ at $100{ }^{\circ} \mathrm{C}$, sonicated to reduce viscosity and centrifuged $10 \mathrm{~min}$ at 15000 rpm. The supernatants were collected and stored at $-80{ }^{\circ} \mathrm{C}$ until further use. Protein concentrations were determined with a commercial protein assay (Pierce BCA reducing agent compatible kit, Thermo Scientific, Waltham, Massachusetts, United State) with BSA as standard. The same protein extract was used for PRM and RPPA assay.

\subsection{Quantification of proteins using PRM mass spectrometry}

\subsubsection{Sample preparation}

After protein concentration determination (RC-DC ${ }^{\mathrm{TM}}$, Bio-Rad, Hercules, California, United State), $30 \mu \mathrm{g}$ of proteins were prepared in tube-gel, as described in Muller, Fornecker, Van Dorsselaer, Cianférani, \& Carapito (2016) with minor adaptations. Briefly, $42.25 \% \mathrm{H}_{2} \mathrm{O}$, $25 \%$ acrylamide/bis-acrylamide, $0.25 \%$ TEMED were added to each sample for a final volume of $100 \mu \mathrm{L}$. Tubes were vortexed and centrifuged. Then $2.5 \%$ of $10 \%$ APS was added, and tubes were rapidly vortexed and centrifuged before polymerization. Proteins were fixed in 
50\% ethanol (Carlo Erba Reagents, Val-de-Reuil, France) and 3\% phosphoric acid, before cutting in small pieces. Gel pieces were then washed three times in 75\% ACN (LC-MS grade, Fisher Chemical, Illkirch, France), $25 \% 25 \mathrm{mM} \mathrm{NH}_{4} \mathrm{HCO}_{3}$, and dehydrated twice in ACN, before reduction and alkylation.

Eleven randomly chosen samples were mixed to be used as a representative matrix for method development and external quality control during the analyses, and prepared as described above.

A concentration-balanced mixture of 20 accurately quantified stable isotope-labelled peptides (Spike Tides ${ }^{\mathrm{TM}}$ TL, JPT Peptide Technologies, Berlin, Germany) corresponding to proteotypic peptides of the 10 biomarker candidates was spiked into the samples before overnight digestion at $37{ }^{\circ} \mathrm{C}$ using a solution of modified porcine trypsin (Promega, Madison, Wiscosin, United State) at a 1:100 (w/w) enzyme-protein ratio.

Peptides were extracted twice for $1 \mathrm{~h}$ under agitation with $60 \% \mathrm{ACN}, 0.1 \%$ formic acid (FA) (Optima LC/MS grade, Fisher Chemical, Illkirch, France), followed by 100\% ACN. After vacuum drying, peptides were resolubilised in $2 \% \mathrm{ACN}, 0.1 \%$ FA to obtain a final concentration of $2 \mu \mathrm{g} / \mu \mathrm{L}$.

\subsubsection{NanoLC-PRM analyses}

NanoLC-PRM analyses were performed on a NanoAcquity UPLC device (Waters, Milford, Massachusetts, United State) coupled to a Q-Exactive Plus mass spectrometer (Thermo Fisher Scientific, Bremen, Germany). Solvent system consisted of $0.1 \%$ FA in $\mathrm{H}_{2} \mathrm{O}$ (solvent A) and 0.1\% FA in ACN (solvent B) (Optima LC/MS grade solvents, Fisher Chemical, Illkirch, France). Peptides (500ng) were separated onto a Symmetry C18 precolumn $(20 \mathrm{~mm} \times 180 \mu \mathrm{m}, 5 \mu \mathrm{m}$ diameter particles; Waters, Milford, Massachusetts, United State) over 3 min at $5 \mu \mathrm{L} / \mathrm{min}$ with $1 \%$ solvent B. Peptides were eluted on a Acquity 
UPLC BEH130 C18 column $(250 \mathrm{~mm} \times 75 \mu \mathrm{m}, 1.70 \mu \mathrm{m}$ particles; Waters, Milford, Massachusetts, United State) at $0.45 \mu \mathrm{L} / \mathrm{min}$ with the following gradient of solvent B: from $1 \%$ to $3 \%$ in $0.5 \mathrm{~min}$, linear from $3 \%$ to $26 \%$ in $54.5 \mathrm{~min}$, linear from $26 \%$ to $35 \%$ in $5 \mathrm{~min}$, and up to $90 \%$ in 1 min. A scheduled PRM method consisting of one full MS1 scan and 16 targeted MS2 scans was developed. The full MS1 scan was collected from $300-1,800 \mathrm{~m} / \mathrm{z}$ at a resolution of 17,500 at $200 \mathrm{~m} / \mathrm{z}$ (AGC target: 3e6, maximum IT: $50 \mathrm{~ms}$ ). Targeted MS2 scans were collected at a resolution of 35,000 at $200 \mathrm{~m} / \mathrm{z}$ (AGC target: 1e6, maximum IT: $128 \mathrm{~ms}$ ) and scheduled with 6-min time windows. Precursors were isolated within a 2-m/z window and fragmented with a NCE of 27.

\subsection{Data treatment}

PRM data were processed with Skyline (version 3.7.1.11099) using appropriate parameters (MacLean et al., 2010). Data were manually curated, and chromatographic peaks manually integrated.

The limits of quantification of each targeted peptide, i.e. the lower limit of quantification (LLOQ) and the upper limit of quantification (ULOQ), were determined using calibration curves. Eight different amounts of the concentration-balanced mixture of heavy-labelled peptides were spiked into the representative matrix. The linear quantification range of each peptide was determined by applying the following criteria: coefficient of variation $(\mathrm{CV}) \leq$ $20 \%$ between analytical triplicates, coefficient of determination $\left(R^{2}\right) \geq 0.99$ between the peptide signal and the injected quantity, $\mathrm{R}^{2} \geq 0.99$ between the back-calculated injected quantity and the real injected quantity, and $80-120 \%$ accuracy by back-calculating the expected injected quantity using the linear regression equation (Table 1).

Accurate quantification of the targeted peptides in the samples was performed by keeping at least three transitions per precursor. Peptide intensity was calculated by summing the 
corresponding transition peak areas. After ensuring that peptide quantity is within its linear range, the ratio between the endogenous and its heavy-labelled peptide counterpart was used to determine the mol amounts of each endogenous peptide. The further calculated concentration was expressed in fmol/ $\mu \mathrm{g}$ of muscular protein (data not shown) and was also reported as $n g / \mu \mathrm{g}$ of muscular protein (Supplementary table 1, for the 43 samples) when the weight of the entire protein was considered. Results expressed as $\mathrm{ng} / \mu \mathrm{g}$ of muscular protein were used for statistical analyses.

\subsection{Quantification of proteins using RPPA}

All primary antibodies were validated for their selectivity/specificity by western blot. An antibody was considered specific against the studied protein when only one band at the expected molecular weight was detected by western blot in a selection of meat samples (data not shown).

Briefly, for RPPA, the muscle extracts of all animals were printed onto nitrocellulose covered slides (Supernova, Grace Biolabs, Bend, Oregon, United States) using a dedicated Aushon 2470 arrayer (Quanterix Corp., Billerica, Massachusetts, United States). Four serial dilutions, ranging from 2000 to $250 \mu \mathrm{g} / \mathrm{ml}$, were printed for each sample, thus allowing to cover the linear part of the antibody signal. In addition, two technical replicates per dilution were printed to check for reproducibility. Arrays were labelled with 10 specific antibodies or without primary antibody (negative control), using a DAKO Autostainer Plus (Agilent, Santa Clara, United States). The slides were incubated with DAKO avidin, biotin and peroxidase blocking reagents (Agilent, Santa Clara, United States) before saturation with TBS containing $0.1 \%$ Tween-20 and 5\% BSA (TBST-BSA). Slides were then probed overnight at $4{ }^{\circ} \mathrm{C}$ with primary antibodies diluted in TBST-BSA. After washes with TBST, arrays were probed with horseradish peroxidase-coupled secondary antibodies (Jackson Immuno Research 
the signal, slides were incubated with Amplification Reagent (Bio-Rad, Hercules, California, United States) for $15 \mathrm{~min}$ at room temperature. The arrays were washed with TBST, probed with Alexa647-Streptavidin (Invitrogen Molecular Probes, Thermo Fisher Scientific, Waltham, Massachusetts, United States) diluted in TBST-BSA for $1 \mathrm{~h}$ and washed again in TBST. For staining of total protein, arrays were incubated $15 \mathrm{~min}$ in $7 \%$ acetic acid and $10 \%$ methanol, rinsed twice in water, incubated 10 min in Sypro Ruby (Thermo Fisher Scientific, Waltham, Massachusetts, United States) and rinsed again. The processed slides were dried by centrifugation and scanned using a GenePix 4000B microarray scanner (Molecular Devices, San José, California, United States). Spot intensity was determined with MicroVigene software (VigeneTech Inc, Carlisle, Massachusetts, Unites States).

Raw data quality control included semi-automated evaluation of the dilution curves for each sample and each antibody to check for a correct sigmoid antibody response curve. Technical replicates were checked for reproducibility. Samples with low overall intensity were removed from further analysis because this can be indicative of protein degradation. Antibodies were validated only if their median intensity over all samples was $>3$ times higher than the median intensity of the negative control slide. Lower limit of detection (LLOD) LLOQ and ULOQ were estimated for each antibody using a pool of all samples that was printed in 10 serial dilutions ranging from 6700 to $13 \mathrm{ug} / \mathrm{ml}$ on each array (Table 2). The dynamic range, between the LLOQ and the ULOQ, covers the concentration range in which the samples were printed (2000 to $250 \mu \mathrm{g} / \mathrm{ml}$ ). Upper limit of detection (ULOD) could not be assessed because of signal saturation. Indeed, scanner settings were chosen to attain saturation for the first dilution of the pooled samples.

The relative abundances of proteins were determined according to the following procedure. First, raw data were normalized using NormaCurve (Troncale et al., 2012), a SuperCurve-based method that simultaneously quantifies and normalizes RPPA data for 
fluorescent background per spot, a total protein stain and potential spatial bias on the slide.

Next, each RPPA slide was median centered and scaled (divided by median absolute deviation). Remaining sample loading effects were corrected individually for each array by correcting the dependency of the data for individual arrays on the median value of each sample over all the arrays using a linear regression.

\subsection{Descriptive and predictive statistical analysis}

Statistical analyses were performed using R 3.5.1 software. Shapiro tests were performed on IMF and shear force values as well as on protein abundances to check for adherence to normality. For the qualification test, and because of the lack of normal distribution of some values, a Wilcoxon test was done to identify differences between the high and low marbling groups whatever the muscle (dataset 1), as well as between tender and tough LT (dataset 2) or SM (dataset 3) muscles. Dataset 1 was composed of SM or LT muscles chosen to keep the 8 lowest and 8 highest values of IMF content. For the tenderness trait, a muscle effect on the values was observed on shear force and of protein abundances (Supplementary Table 1). The qualification test was therefore done separately for LT (dataset 2, 5 LT samples with the lowest and 5 with the highest values of shear force) and ST (dataset 3, 5 SM samples with the lowest and 5 with the highest values of shear force) muscles. Differences were considered as significant when $\mathrm{p}$-value was $<0.05$, and a tendency was recorded when $\mathrm{p}$-value ranged from 0.05 to 0.15 .

For the verification steps, the capacity to predict the IMF or shear force values using the abundance of one protein was tested. Data obtained for the 43 muscles without any classification were used to develop 54 different linear models to predict either IMF or shear force values. Each linear prediction model was composed of the abundance of one protein. For the shear force prediction, the muscle effect was added to the equation, in order to take into consideration the differences in shear force and protein abundances between muscles. 
We also developed 54 binomial logistic regression with logit model to test the ability of one protein to classify each muscle into lean, fat, tender or tough classes. Lean and fat classes consisted of muscles with IMF values lower and higher than $3.5 \%$, respectively, which is the threshold at which French meat consumers are able to distinguish lean from fat meat (Berthelot \& Gruffat, 2018). Consequently, the lean $(\mathrm{n}=21)$ and fat $(\mathrm{n}=22)$ groups had significant $(\mathrm{P}<0.001)$ divergent values of IMF content $(2.39 \pm 0.94$ and $6.08 \pm 1.02 \%$, respectively). The tender and tough groups consisted of muscles with shear force values lower and higher than $42 \mathrm{~N} / \mathrm{cm}^{2}$, which corresponds to the threshold proposed by Destefanis, Brugiapaglia, Barge, \& Dal Molin (2008). Consequently, the tender $(n=27)$ and though $(n=$ 16) groups had significant $(\mathrm{P}<0.001)$ divergent values of shear force $(31.81 \pm 4.07$ and 54.17 $\pm 10.22 \mathrm{~N} / \mathrm{cm}^{2}$, respectively). Each logistic model predicted the probability of the muscle to move from a reference cluster to a superior cluster of the predicted variable (i.e. tenderness or adiposity). For all binomial logistic models predicting tenderness, the tough cluster was the reference cluster, and for those predicting adiposity, the reference cluster was the lean cluster. To predict the tenderness classes, the abundance of one protein and the muscle factor were included in each logistic model. To predict the adiposity classes, only the abundance of one protein was included in each model.

The validation of each of the 54 linear and 54 logistic models was performed using a bootstrap procedure, because the number of muscle samples did not allow us to perform an external validation (Tan, Steinbach, \& Kumar, 2006). The bootstrap procedure was repeated 500 times to generate 500 bootstrap samples, for each developed model. The number of times the protein coefficient in the model was significant was counted over the 500 repetitions. Only proteins for which $\geq 60 \%$ of the bootstrap samples had a significant protein coefficient were selected for the next step, which is the quality evaluation of the models. 
To evaluate the quality of the developed linear models, three criteria were considered: the root mean square errors of prediction (Kobayashi \& Salam, 2000), the mean prediction error (MPE) (Yan, Frost, Keady, Agnew, \& Mayne, 2007) and $\mathrm{R}^{2}$. The MPE and $\mathrm{R}^{2}$ were used to describe the prediction accuracy and the precision of the model, respectively. The prediction models were considered to have a high or good accuracy when MPE ranged from 0.10 to 0.30 and to have a high precision when the $\mathrm{R}^{2}$ was the closest to 1 . The quality of the developed logistic models was assessed by four criteria: the success rate, the accuracy, the sensitivity and the area under the curve (AUC). The AUC was measured using the "ROCR" package in R (Sing, Sander, Beerenwinkel, \& Lengauer, 2005). The prediction models were considered to have a good to high accuracy when the AUC was higher than 0.60, a threshold commonly used in biomarkers triage process (Capello et al., 2017; Yoneyama et al., 2016). Final models were constructed with the mean of protein coefficients that were significant among the 500 repetitions (i.e. significant models over the 500 repetitions), and consequently metrics from these significant models were used to calculate mean criteria for linear and logistic models.

\section{Results}

\subsection{Selection of biomarkers for testing in evaluation and verification steps}

Potential muscular biomarkers for sequential validation studies were selected among protein candidates that met at least two of the following criteria : 1) inclusion in the compendium of potential biomarkers of marbling (Bazile, Picard, Chambon, Valais, \& Bonnet, 2019; Ceciliani et al., 2018; Thornton et al., 2017) or tenderness (Picard et al., 2017); 2) identified as differentially abundant by in-depth quantitative proteomic analyses of two groups of Rouges des Prés bovine breed strongly divergent by marbling (Bazile et al., 2019) or tenderness (Picard et al., 2019); 3) a dynamic muscular protein concentration range from 
$10^{2}$ and $10^{5}$ or 0.1 to $100 \mathrm{ng} / \mathrm{mg}$ of protein assuming that the suitable minimal range of detection proposed for plasma (Surinova et al., 2011) is accurate for muscular protein. As a result, a total of 10 potential biomarkers were selected for further qualification and verification tests. The 10 proteins consisted of Malate dehydrogenase (MDH1), $\beta$-enolase 3 (ENO3), Retinal dehydrogenase 1 (ALDH1A1), Triosephosphate isomerase (TPI1), $\alpha \mathrm{B}$ crystallin (CRYAB), Heat shock protein beta-1 (HSPB1), Peroxiredoxin 6 (PRDX6), Myosin 1 (heavy chain-IIx, MYH1), Troponin T slow skeletal muscle (TNNT1), and Four and a half LIM domains 1 (FHL1).

\subsection{Quantitative PRM and semi-quantitative RPPA assay developments}

Two peptide analytes per protein (distinguished as P1 and P2 after the gene name of the protein) were configured into a PRM-MS assay, and stable isotope-labelled peptides were used as internal standards. The analytical performances of the PRM assays were determined by generating a response curve for each of the 20 targeted peptides. Performance characteristics of the assays for the 10 candidate proteins are summarized in Table 1 . The medium analytical coefficient of variation at the lower limit of quantification (LLOQ) and across all peptides was $4.22 \%$. The median lower limit of detection (LLOD) was $0.23 \mathrm{ng} / \mu \mathrm{g}$ protein and the median LLOQ was $0.25 \mathrm{ng} / \mu \mathrm{g}$ protein. When applied to the 43 muscular samples, the absolute quantification failed for TNNT1_P2, and for ALDH1A1 with both peptides, because the quantitative values were below the LLOQ. The absolute quantification failed for PRDX6_P1 due to the lack of a reliable calibration curve and consequently no LLOQ has been calculated. Protein abundances were above the ULOQ for MYH1_P2 in half of the 43 muscular samples (data not shown).

Performance characteristics of the RPPA assays for the 10 candidate proteins are summarized in Table 2. The median analytical coefficient of variation at the LLOQ and across 
all proteins was $13 \%$. The median LLOD was $100 \mathrm{ng} / \mu \mathrm{l}$ of total protein and the median LLOQ was $500 \mathrm{ng} / \mu \mathrm{g}$ of total protein (Table 2).

The quantitative values of the 9 proteins assayed by RPPA were correlated with the absolute PRM quantification for the 43 muscular samples. The values of the significant $(\mathrm{P}<$ 0.05) Pearson correlation coefficients were more than 0.60 for CRYAB, HSPB1 (both peptides) and MYH1_P1, and ranged between 0.34 and 0.60 for TNNT1, ENO3, TPI1 (both peptides) and MYH1_P2, indicating that the PRM and RPPA assays are in good and moderate agreement for 6 proteins. There was no agreement between the quantitative values assayed by PRM and RPPA for MDH1, FHL1 and PRDX6 (data not shown).

\subsection{Qualification of candidate biomarkers in extreme groups of marbling and tenderness.}

The candidate biomarkers were subjected to the qualification test using PRM, RPPA and sample sets specific for marbling or tenderness, in order to demonstrate that the differential candidate abundance observed in the discovery step is confirmed by at least an alternative targeted method, as requested within the biomarker pipeline (Rifai et al., 2006).

The marbling dataset 1 was composed of 16 muscles chosen for their high $(7.06 \pm 0.63$ $\mathrm{mg} / \mathrm{g}$ of fresh muscle, $\mathrm{n}=8)$ or low $(1.26 \pm 0.56 \mathrm{mg} / \mathrm{g}$ of fresh muscle, $\mathrm{n}=8)$ values of IMF, and as expected they were thus very divergent $(\mathrm{P}<0.001)$ for marbling (Figure 1; Supplementary Table 2). When assayed by PRM, the abundances of MYH1 and TPI1 (especially when quantified using peptide 2$)$ were significantly $(\mathrm{P}<0.05)$ lower while the abundance of MDH1 was higher in the highly versus lightly marbled muscles. The abundances of CRYAB and FHL1 quantified using peptides 1 tended $(\mathrm{P}<0.13)$ to be the highest in the highly marbled muscles. When assayed by RPPA, the abundances of ALDH1A1 and CRYAB were higher while the abundance of MYH1 was lower in highly versus lowly marbled muscles. Moreover, the abundances of FHL1 and TNNT1 tended $(\mathrm{P}<$ 
0.13) to be higher while the abundance of TPI1 tended to be lower in highly marbled muscles (Figure 1; Supplementary Table 2).

Two tenderness sample sets were composed of 10 LT (dataset 2) or 10 SM (dataset 3) samples chosen for their high $\left(38.17 \pm 6.19 \mathrm{~N} / \mathrm{cm}^{2}\right.$ for LT; or $66.24 \pm 7.47 \mathrm{~N} / \mathrm{cm}^{2}$ for $\mathrm{SM}, \mathrm{n}=$ $5 /$ per muscle, tough) or low $\left(25.79 \pm 1.61 \mathrm{~N} / \mathrm{cm}^{2}\right.$ for LT or $33.90 \pm 2.13 \mathrm{~N} / \mathrm{cm}^{2}$ for $\mathrm{SM}, \mathrm{n}=$ 5/per muscle, tender) shear force values ( $\mathrm{P}=0.008$, Figure 2; Supplementary Table 3$)$, to take into account a muscle significant effect on tenderness and on most of the protein abundances

(Supplementary Table 1). As expected, the two groups of shear force were very divergent for each muscle. For LT muscle, HSPB1, qualified both by PRM and RPPA assays, was the sole protein differentially abundant between groups and as expected its abundance was the lowest in tender LT. A tendency $(\mathrm{P}=0.12)$ for a higher abundance of TPI1 assayed by RPPA was observed in tender LT. For SM muscle, MDH1 and TNNT1 were qualified when assayed by PRM and their abundance was higher in the tender compared to tough SM. We recorded a tendency $(\mathrm{P}<0.15)$ for higher abundances of ENO3_P2, PRDX6_P2 assayed by PRM, and a higher abundance of TNNT1 assayed by RPPA in the tender compared to tough SM (Figure 2; Supplementary Table 3).

\subsection{Verification studies for candidate biomarkers of marbling}

The PRM and RPPA assays were applied to the 43 muscular samples (whatever the muscle) to assess the performances of the biomarker candidates both for predicting the IMF values using linear regression, and to distinguish two classes (fat or lean class) of muscles according to their IMF content using univariate logistic regression.

Out of the protein abundances assayed, the abundance of MYH1_P1, MYH1_P2, TPI1_P2 assayed by PRM as well as ALDH1A1, MYH1 or CRYAB assayed by RPPA significantly predicted IMF values in the linear regression in at least $60 \%$ of the 500 
repetitions done in the bootstrap procedure (see equations 6 to 11, Table 3). However, the precision of the predictions were low, since the $R^{2}$ ranged from 0.11 (for CRYAB) to 0.23 (for MYH1_P1), and the accuracies (MPE) were between 0.45 and 0.50 . Nevertheless, these results highlighted that one protein abundance accounted for 11 to $23 \%$ of the variability of IMF values in SM and LT muscles.

Logistic regression models based on the abundance of the 27 assayed proteins were developed to identify the proteins able to classify muscles to the lean or fat class. Only 3 abundances assayed by PRM yielded significant and good predictive models. The logistic regression model of TPI1_P2, MYH1_P1 and MYH1_P2 yielded an AUC of 0.75, 0.62 and 0.72, respectively (Table 4). The models yielded accuracies of 56 to $62 \%$ for fat class and sensitivities between 60 and 77\%. For the lean class, accuracies of the models ranged from 64 to $69 \%$ and the sensitivities were between 49 and $67 \%$.

\subsection{Verification studies for candidate biomarkers of tenderness}

The ability of one of the 27 protein abundances to predict shear force values thanks to a linear regression, or to distinguish two classes (tender or tough class) of muscles according to their shear force with univariate logistic regression was done for 43 samples of muscle but with the inclusion of a muscle factor.

Out of the 27 protein abundances assayed, the abundance of MDH1_P1, MDH1_P2, ENO3_P2, PRDX6_P2 and TNNT1_P1 assayed by PRM were significant in the linear regression to predict shear force values in at least $60 \%$ of the 500 repeats done in the bootstrap procedure (see equations 1 to 5, Table 3 ). The precisions of the prediction $\left(\mathrm{R}^{2}\right)$ ranged from 0.40 to 0.50 and the MPE values scored between 0.23 and 0.26 . Thus, among these proteins considered one by one, one protein abundance accounted for 40 to $50 \%$ of the variability of 
IMF values in SM and LT muscles. Any model by logistic regression for tenderness were obtained probably due to the muscle effect that decreases the statistical power of the models.

\section{Discussion}

An initial set of 10 muscular biomarker candidates were selected, based on in-depth proteomic analysis of muscles differing in marbling (Bazile et al., 2019) and tenderness (Picard et al., 2019), and a review of literature (Ceciliani, Lecchi, Bazile, \& Bonnet, 2018; Picard et al., 2017). The 10 candidate biomarkers were tested using a LC-MS/MS-based and an antibody-based method for the qualification and verification steps of the biomarker discovery pipeline proposed by Rifai et al. (2006). Among these 10 muscular biomarker candidates, 8 were qualified as biomarkers of marbling or tenderness, and the abundance of a protein alone was shown to predict IMF content or shear force. Two biomarkers were shown to distinguish classes of muscles with low and high levels of marbling. The high number of biomarkers successfully confirmed by the present study may result from our choice to verify few biomarker candidates, as well as from the relevant sample size (up to 10 samples per group) and the stringent power calculation that we have applied during the discovery phases (Bazile et al., 2019) in agreement with the recommendations from Drabovich et al. (2015).

\subsection{Biomarkers of marbling}

Considering the biomarker candidates of marbling, the present results qualified MYH1 and TPI1 both by PRM and RPPA methods, MDH1 by PRM, as well as ALDH1A1 and CRYAB by RPPA. The differential abundance previously shown by proteomic studies in the same breed but from divergent samples (Bazile et al., 2019) was thus confirmed using new methods. Out of these 5 qualified biomarkers, MYH1, ALDH1A1, TPI1 or CRYAB were verified as their abundance was able to explain the variability of IMF content values, and the 
abundance of MYH1 or TPI1 was also able to distinguish lean or fat muscle groups. These results are consistent with the muscular physiology and the molecular basis of lipid deposition in muscle. Indeed, muscles use both carbohydrates and fatty acids as energy sources for the production of free energy and muscular contraction, according to a ratio that differs between glycolytic and oxidative fibres. Oxidative muscles generally contain more lipids than glycolytic muscles. Consistently, TPI1, a glycolytic enzyme, and MYH1, coding for the myosin MyHC-2x isoform related to fast glycolytic fibre (Schiaffino \& Reggiani, 2011), were less abundant in high marbled muscle, and were inversely related to IMF values in predictive equations. The highest abundances of ALDH1A1 and CRYAB in highly marbled muscle is also consistent with pathways related to lipid deposition. ALDH1A1 is a retinal dehydrogenase that irreversibly oxidizes retinaldehyde to retinoic acid (Takeda et al., 2016). Retinoic acid was shown to have a pivotal regulatory role in the balance between lipid synthesis (lipogenesis and fatty acid uptake) and degradation (lipolysis and fatty acid oxidation), at least in monogastric species. Indeed, as reviewed by Bazile et al. (2019), retinoic acid was shown to stimulate lipid deposition in human adipose-derived stem cells, and lipid oxidation in mature adipocytes. Moreover, (Bazile et al., (2019) previously proposed that an ALDH1A1-mediated increase in retinoic acid content mediates an increase in the abundance of the small heat shock protein $\mathrm{CRYAB}$, which is a retinoic acid-responsive gene (Takeda et al., 2016). Thus, the highest abundance of CRYAB in highly marbled Rouge des Prés LT muscle first seen by Bazile et al. (2019), confirmed by the present results in LT and SM muscles, may sustain the higher oxidative metabolism expected in highly marbled muscles. Lastly, the 4 biomarkers validated may be valuable biomarkers of marbling in other breeds, since TPI1, MYH1, ALDH1A1 or CRYAB (for review, Bazile et al., 2019; Ceciliani et al., 2018; Thornton et al., 2017) were reported as differentially abundant by proteomics studies in up to four early-maturing bovine breeds known to deposit lipids. 
Moreover, the present results suggest that TNNT1, FHL1 and MDH1 may be part of the molecular signature of marbling, even if they were not retained as biomarkers of marbling because their abundance between highly and slightly marbled muscles tended to differ (TNNT1, FHL1) or did not allow to predict IMF values (MDH1). In agreement with this hypothesis, among the 47 proteins that were differentially abundant across the adiposity groups (Bazile et al., 2019), 4 were contractile or structural proteins classically used for the muscular fibre classification. Of these, a higher abundance of slow-type proteins such as TNNT1 previously observed in Rouge des Prés cows (Bazile et al., 2019) as well as in others breeds of cattle (raised in the Pacific Northwestern Unites States and Canada) divergent by marbling (Thornton et al., 2017), tended to be confirmed in the present study. In bovine, we were the first to observe a tendency for a higher abundance of FHL1 assayed by shotgun proteomics, in muscle of highly marbled Rouge des Prés bovines. An overexpression of the FHL1 gene was also reported when obese-type pigs were compared to lean-type ones (Yang et al., 2017). A hypothetical functional link between FHL1 and marbling may be that FHL1 was shown to activate myostatin signalling, in skeletal muscle of mice (Lee, Lori, Wells, \& Kemp, 2015). Moreover, in human, a deletion of the entire FHL1 gene was shown to induce a muscle hypertrophy, a very mild fatty striation of the muscle shown by magnetic resonance imaging scan and reduced subcutaneous fat (Willis et al., 2016). If we assume that similar FHL1 signalling occurs in bovine, a higher abundance of FHL1 may contribute to a higher myostatin signalling and IMF deposition by promoting the commitment and differentiation of multi-potent mesenchymal cell lines into the adipogenic lineage rather than the myogenic lineage (Bonnet, Cassar-Malek, Chilliard, \& Picard, 2010). Lastly, the differential abundance of MDH1 (cytoplasmic malate dehydrogenase) according to marbling was confirmed, although its abundance alone was not able to predict IMF values or fatness classes. MDH1 is involved in reduced nicotinamide adenine dinucleotide phosphate (NADPH) supply for de 
novo fatty acid synthesis and is considered as a lipogenic enzyme. A significant correlation between malic enzyme activity (MDH1) and IMF values in the rectus abdominis and semitendinosus muscles from Limousin, Angus and Japanese Black cross Angus steers was previously reported (Bonnet et al., 2007). A higher MDH1 activity was also recorded in the more oxidative and marbled rectus abdominis than in the semitendinosus (fast glycolytic) muscle regardless of the breed (Bonnet et al., 2007).

\subsection{Biomarkers of tenderness}

Considering the biomarker candidates of tenderness, the present results qualified HSPB1 (in LT) and TNNT1 (in SM) assayed both by PRM and RPPA methods, and MDH1, PRDX6 and ENO3 assayed by PRM as biomarkers in SM muscle, since we have confirmed the differential abundance previously shown by proteomic studies (Picard et al., 2017). Of these, MDH1, PRDX6 TNNT1 and ENO3 were both differentially abundant between tender and tough SM and the abundance of one protein explained up to $50 \%$ of the variability of shear force value. We validated PRDX6 as a biomarker of tenderness in the Rouge des Prés bovines, as in several other bovine breeds (Picard et al., 2017). It is a bifunctional protein with two activities: glutathione peroxidase and phospholipase A2. Its implication in tenderness could be through the postmortem detoxification of reactive oxygen species (ROS) in the cells. Moreover, decrease of ROS has been described to enhance the function of $\mu$-calpain involved in meat tenderization, which is in accordance with the correlation between PRDX6 and $\mu$ calpain described by Picard et al., (2017). Our results also highlight a strong link between the abundance of MDH1 and beef tenderness. Beside its lipogenic function, this protein was described to play crucial roles in energy and cellular metabolic pathways, such as in the malate-aspartate shuttle and in the citric acid cycle, to produce energy for many biological functions in aerobic tissues. To our knowledge, we are the first to propose MDH1 as a positive biomarker and predictor of beef tenderness. A relationship between TNNT1 (or 
TNNT3 fast isoforms) and tenderness has been described by several studies, and Troponin was described as an indicator of tenderization since a fragment appears early postmorten (Picard et al., 2017). Glycolytic enzymes such as ENO3 (skeletal muscle isoform of enolase) have also been associated with tenderness development in several breeds (Picard et al., 2017). In the present study, a higher abundance of ENO3 in the most tender SM was confirmed by the PRM assay (with peptide 2) and this abundance was able to explain the variability of beef tenderness. In line with these statistical relationships, glycolysis is the first biological pathway mobilized for postmortem production of ATP and its rate depends mainly on NAD ${ }^{+}$ availability, involving enzymes such as MDH1 as described above.

Even if HSPB1 was confirmed as differentially abundant according to shear force values in LT, its abundance alone was not able to predict shear force values from the 2 studied muscles. The HSPB1 protein appeared to be differentially abundant only in LT muscle, which is consistent with a muscle type effect already described for small HSPs such as HSPB1 (Picard et al., 2017). This protein, involved in many molecular pathways such as response to heat and stress, regulation and stabilization of myofibrillar proteins, protection of actin and desmin, and negative regulation of apoptosis, has been proposed as a biomarker candidate of beef tenderness in several breeds as reviewed by Picard et al. (2017). However, the relation between HSPB1 abundance and tenderness was different according to the contractile and metabolic properties of muscles. Most of the time, a positive relationship between HSPB1 and tenderness was reported in the most glycolytic muscles, while a negative relationship was reported in the most oxidative ones (Picard et al., 2017). The lower abundance of HSPB1 in the tender LT that we report in the present study is in line with this general rule, since Rouge des Prés LT muscle was reported to have slow oxidative characteristics and to contain a low proportions of fast glycolytic fibres (Couvreur et al., 2019). A study in knock-out HSPB1 mice showed that calcium homeostasis, muscle structure and contraction and energy 
metabolism were impacted by the absence of HSPB1, supporting a role of HSPB1 in tenderization (Picard et al., 2016). In conclusion, the biomarkers of tenderness that we validated in this study are coherent with the main biological functions involved in postmortem muscle modifications namely energetic metabolism, contraction, and cellular stress.

\subsection{Added-values of the combination of PRM and RPPA methods}

It is noteworthy that some biomarkers were qualified and verified either when assayed by PRM, by RPPA or by both methods. Out of the 8 proteins that were shown to have statistical relationships with marbling or tenderness, only MHY1 was selected in models for marbling whatever the method of quantification. Despite the accuracies of the PRM and RPPA assays reported here, methodological specificities have provided some differences in quantitative values as exemplified by the lack of PRM results for ALDHI1A, or poor agreement for MDH1 and PRDX6 candidates. Despite those discrepancies, we have chosen to combine PRM and RPPA results for two reasons : to take advantage of two orthogonal methods and because both methods allow reaching sensitivities in the $\mathrm{ng} / \mathrm{mg}$ to $\mu \mathrm{g} / \mathrm{mg}$ range (Solier \& Langen, 2014), compatible with the expected abundances of the 10 selected candidate proteins. While PRM assays depend on the use of proteotypic standard peptides ensuring high specificity and allowing an absolute quantification assuming an effective trypsin digestion, RPPA assays rely on indirect fluorescent readout, require the use of a specific antibody against each protein and are highly dependent on the quality and the preservation of the sample. Our choice was very efficient as out of the 6 proteins quantified with similar abundance by PRM and RPPA, 5 proteins (MHY1, TPI1, CRYAB, HSPB1, TNNT1) were qualified as biomarkers of tenderness or marbling by both methods. This result, together with the 8 proteins that were verified for their statistical performance in the prediction of tenderness and marbling, demonstrate that the combination of both methods was very relevant to screen for biomarker proteins in the present context. Strengths and weaknesses of antibody- 
versus MS-based validation methods have been largely reviewed and added-values and discrepancies obtained when combining both methods have been previously illustrated in the context of clinical studies (Drabovich et al., 2015; Solier \& Langen, 2014; Surinova et al., 2011; Yoneyama et al., 2016).

\section{Conclusion}

To conclude, we were able to quantify 9 and 10 candidate biomarkers by PRM and RPPA, respectively. Of these, MDH1, TNNT1, ENO3, and PRDX6 were effective to predict tenderness while marbling was predicted by TPI, MYH1, and with lower efficacy by ALDH1A1 and CRYAB, based on their confirmed differential abundances between divergent groups and on their mathematical relationships with these meat-eating qualities. However, these relationships are not precise enough to provide a specific test based on a single protein, even if they showed that the abundance of one protein explains up to $50 \%$ of tenderness. Nevertheless, the PRM and RPPA assays developed in the present study constitute a very promising starting point for a further large-scale sample screening for the final validation of biomarkers of marbling and tenderness. First, because of the higher variability of tenderness and protein abundances within SM muscle, SM should be more accurate than the LT muscle to screen meat-eating qualities. Second, the present PRM-related quantitative values provide reference values to test simplest quantitative method, and RPPA assays are a first screening of specific antibodies that pave the way for next step of biomarker evaluation. Lastly, we will try to combine up to 4 proteins to increase the power of the prediction, which implies using a higher sample size than in the present study, the combination of several proteins being shown to increase the predictive accuracy. Once a good level of prediction will be achieved by considering the abundance of up to four proteins for marbling or tenderness, we will developed a multiplex protein quantification assay, in order to provide beef industry with an original and low cost tool for meat grading. 


\section{Declaration of Competing Interest}

The authors declared no conflicts of interest.

\section{Acknowledgements}

The authors thank the SICA Rouge des Prés, especially A. Valais and G. Aminot, for animal handling, and sampling. We thank S. Couvreur and G. Le Bec (Ecole Supérieure d'Agriculture (ESA) Angers) for muscle sampling, as well as IMF content and shear force assays. We thank N. Guivier-Fredot for protein extraction. This work was supported by INRAE-Phase Division (Funding of the RefQuant project). Mass spectrometry experiments were supported by the French Proteomic Infrastructure (ProFI; ANR-10-INBS-08-03).

\section{Appendix A. Supplementary data}

Were included after the tables

\section{References}

Akbani, R., Becker, K.-F., Carragher, N., Goldstein, T., de Koning, L., Korf, U., Liotta, L., Mills, G. B., Nishizuka, S. S., Pawlak, M., Petricoin, E. F., Polard, H. B., Serrels, B., \& Zhu, J. (2014). Realizing the Promise of Reverse Phase Protein Arrays for Clinical, Translational, and Basic Research: A Workshop Report. Molecular \& Cellular Proteomics, 13(7), 1625-1643.

Baik, M., Kang, H. J., Park, S. J., Na, S. W., Piao, M., Kim, S. Y., Fassah, D. M., \& Moon, Y. S. (2017). TRIENNIAL GROWTH AND DEVELOPMENT SYMPOSIUM: Molecular mechanisms related to bovine intramuscular fat deposition in the longissimus muscle. Journal of Animal Science, 95(5), 2284-2303. 
Bazile, J., Picard, B., Chambon, C., Valais, A., \& Bonnet, M. (2019). Pathways and biomarkers of marbling and carcass fat deposition in bovine revealed by a combination of gel-based and gel-free proteomic analyses. Meat Science, 156, 146-155. Berthelot, V., \& Gruffat, D. (2018). Composition en acides gras des muscles. In P. Nozière, D. Sauvant, \& L. Delaby, Quae (Eds.), Alimentation des Ruminants. Apports Nutritionnels. Besoins et Réponses des Animaux. Rationnement. Tables des Valeurs des Aliments (pp. 225-235). Versailles, France.

Bonnet, M., Cassar-Malek, I., Chilliard, Y., \& Picard, B. (2010). Ontogenesis of muscle and adipose tissues and their interactions in ruminants and other species. Animal, 4(7), 1093-1109.

Bonnet, M., Faulconnier, Y., Leroux, C., Jurie, C., Cassar-Malek, I., Bauchart, D., Boulesteix, P., Pethick, D., Hocquette, J.-F., \& Chilliard, Y. (2007). Glucose-6-phosphate dehydrogenase and leptin are related to marbling differences among Limousin and Angus or Japanese Black × Angus steers,. Journal of Animal Science, 85(11), 2882-2894. Borràs, E., \& Sabidó, E. (2017). What is targeted proteomics? A concise revision of targeted acquisition and targeted data analysis in mass spectrometry. Proteomics, 17(1718), 1700180.

Bourmaud, A., Gallien, S., \& Domon, B. (2016). Parallel reaction monitoring using quadrupole-Orbitrap mass spectrometer: principle and applications. Proteomics, 16(1516), 2146-2159.

Capello, M., Bantis, L. E., Scelo, G., Zhao, Y., Li, P., Dhillon, D. S., Patel, N. j., Kundnani, D. L., Wang, H., \& Abbruzzese, J. L. (2017). Sequential validation of bloodbased protein biomarker candidates for early-stage pancreatic cancer. JNCI: Journal of the National Cancer Institute, 109(4). 
Ceciliani, F., Lecchi, C., Bazile, J., \& Bonnet, M. (2018). Proteomics research in the adipose tissue. In Springer (Eds.), Proteomics in domestic animals: from farm to systems biology (pp. 233-254).

Couvreur, S., Le Bec, G., Micol, D., \& Picard, B. (2019). Relationships Between Cull Beef Cow Characteristics, Finishing Practices and Meat Quality Traits of Longissimus thoracis and Rectus abdominis. Foods, 8(4), 141.

Destefanis, G., Brugiapaglia, A., Barge, M. T., \& Dal Molin, E. (2008). Relationship between beef consumer tenderness perception and Warner-Bratzler shear force. Meat Science, 78(3), 153-156.

Drabovich, A. P., Martinez-Morillo, E., \& Diamandis, E. P. (2015). Toward an integrated pipeline for protein biomarker development. Biochimica et Biophysica Acta (BBA)Proteins and Proteomics, 1854(6), 677-686.

Farmer, L. J., \& Farrell, D. T. (2018). Review: Beef-eating quality: a European journey. Animal, 12(11), 2424-2433.

Gallien, S., Duriez, E., Crone, C., Kellmann, M., Moehring, T., \& Domon, B. (2012). Targeted proteomic quantification on quadrupole-orbitrap mass spectrometer. Molecular \& Cellular Proteomics, 11(12), 1709-1723.

Kobayashi, K., \& Salam, M. U. (2000). Comparing simulated and measured values using mean squared deviation and its components. Agronomy Journal, 92(2), 345-352. Lee, J. Y., Lori, D., Wells, D. J., \& Kemp, P. R. (2015). FHL1 activates myostatin signalling in skeletal muscle and promotes atrophy. FEBS Open Bio, 5, 753-762. MacLean, B., Tomazela, D. M., Shulman, N., Chambers, M., Finney, G. L., Frewen, B., ... MacCoss, M. J. (2010). Skyline: an open source document editor for creating and analyzing targeted proteomics experiments. Bioinformatics, 26(7), 966-968. 
Meyer, J. G., \& Schilling, B. (2017). Clinical applications of quantitative proteomics using targeted and untargeted data-independent acquisition techniques. Expert Review of Proteomics, 14(5), 419-429.

Muller, L., Fornecker, L., Van Dorsselaer, A., Cianférani, S., \& Carapito, C. (2016). Benchmarking sample preparation/digestion protocols reveals tube-gel being a fast and repeatable method for quantitative proteomics. Proteomics, 16(23), 2953-2961.

Peterson, A. C., Russell, J. D., Bailey, D. J., Westphall, M. S., \& Coon, J. J. (2012). Parallel reaction monitoring for high resolution and high mass accuracy quantitative, targeted proteomics. Molecular \& Cellular Proteomics, 11(11), 1475-1488.

Picard, B., Gagaoua, M., Al Jammas, M., \& Bonnet, M. (2019). Beef tenderness and intramuscular fat proteomic biomarkers: Effect of gender and rearing practices. Journal of Proteomics, 200, 1-10.

Picard, B., Gagaoua, M., \& Hollung, K. (2017). Gene and protein expression as a tool to explain/predict meat (and fish) quality. In New aspects of meat quality (pp. 321-354). Elsevier.

Picard, B., Kammoun, M., Gagaoua, M., Barboiron, C., Meunier, B., Chambon, C., \& Cassar-Malek, I. (2016). Calcium Homeostasis and Muscle Energy Metabolism Are Modified in HspB1-Null Mice. Proteomes, 4(2), 17. https://doi.org/10.3390/proteomes4020017 Rifai, N., Gillette, M. A., \& Carr, S. A. (2006). Protein biomarker discovery and validation: the long and uncertain path to clinical utility. Nature Biotechnology, 24(8), 971.

Schiaffino, S., \& Reggiani, C. (2011). Fiber Types in Mammalian Skeletal Muscles. Physiological Reviews, 91(4), 1447-1531. 
Shi, T., Song, E., Nie, S., Rodland, K. D., Liu, T., Qian, W.-J., \& Smith, R. D. (2016). Advances in targeted proteomics and applications to biomedical research. Proteomics, 16(15-16), 2160-2182.

Sing, T., Sander, O., Beerenwinkel, N., \& Lengauer, T. (2005). ROCR: visualizing classifier performance in R. Bioinformatics, 21(20), 3940-3941.

Solier, C., \& Langen, H. (2014). Antibody-based proteomics and biomarker researchcurrent status and limitations. Proteomics, 14(6), 774-783.

Surinova, S., Schiess, R., Hüttenhain, R., Cerciello, F., Wollscheid, B., \& Aebersold, R. (2011). On the Development of Plasma Protein Biomarkers. Journal of Proteome Research, 10(1), 5-16.

Takeda, K., Sriram, S., Chan, X. H. D., Ong, W. K., Yeo, C. R., Tan, B., Lee, S.-A., Kong, K. V., Hoon, S., Jiang, H., Yuen, J. J., Perumal, J., Agrawal, M., Vaz, C., So, J., Shabbir, A., Blaner, W. S., Olivo, M., Han, W., Tanavde, V., Toh, S.-A., \& Sugii, S. (2016). Retinoic Acid Mediates Visceral-Specific Adipogenic Defects of Human AdiposeDerived Stem Cells. Diabetes, 65(5), 1164-1178.

Tan, P.-N., Steinbach, M., \& Kumar, V. (2006). Introduction to Data Mining (1st ed.). Pearson International Edition.

Thornton, K. J., Chapalamadugu, K. C., Eldredge, E. M., \& Murdoch, G. K. (2017). Analysis of Longissimus thoracis Protein Expression Associated with Variation in Carcass Quality Grade and Marbling of Beef Cattle Raised in the Pacific Northwestern United States. Journal of Agricultural and Food Chemistry, 65(7), 1434-1442.

Troncale, S., Barbet, A., Coulibaly, L., Henry, E., He, B., Barillot, E., Dubois, T., Hupe, P., \& de Koning, L. (2012). NormaCurve: A SuperCurve-Based Method That Simultaneously Quantifies and Normalizes Reverse Phase Protein Array Data. Plos One, 7(6), e38686. 
Vidova, V., \& Spacil, Z. (2017). A review on mass spectrometry-based quantitative proteomics: Targeted and data independent acquisition. Analytica Chimica Acta, 964, $7-$

703

704

705

706

707

708

709

710

711

712

713

714

715

716

717

718

719

720

721

722 23.

Willis, T. A., Wood, C. L., Hudson, J., Polvikoski, T., Barresi, R., Lochmüller, H., Bushby, K., \& Straub, V. (2016). Muscle hypertrophy as the presenting sign in a patient with a complete FHL1 deletion. Clinical Genetics, 90(2), 166-170.

Wu, W., Dai, R.-T., \& Bendixen, E. (2019). Comparing SRM and SWATH Methods for Quantitation of Bovine Muscle Proteomes. Journal of Agricultural and Food Chemistry, 67(5), 1608-1618. https://doi.org/10.1021/acs.jafc.8b05459.

Yan, T., Frost, J. P., Keady, T. W. J., Agnew, R. E., \& Mayne, C. S. (2007). Prediction of nitrogen excretion in feces and urine of beef cattle offered diets containing grass silage. Journal of Animal Science, 85(8), 1982-1989.

Yang, Y., Liang, G., Niu, G., Zhang, Y., Zhou, R., Wang, Y., Mu, Y., Tang, Z., \& Li, K. (2017). Comparative analysis of DNA methylome and transcriptome of skeletal muscle in lean-, obese-, and mini-type pigs. Scientific Reports, 7, 39883.

Yoneyama, T., Ohtsuki, S., Honda, K., Kobayashi, M., Iwasaki, M., Uchida, Y., Okusaka, T., Nakamori, S., Shimahara, M., \& Ueno, T. (2016). Identification of IGFBP2 and IGFBP3 as compensatory biomarkers for CA19-9 in early-stage pancreatic cancer using a combination of antibody-based and LC-MS/MS-based proteomics. PLoS One, 11(8), e0161009. 
724

725

726

727

728

729

730

731

732

733

734

735

736

737

738

739

740

741

742

743

\section{Figure caption}

Figure 1. Intramuscular fat content and protein abundances in longissimus thoracis (LT) or semimembranosus (SM) muscles. The qualification step (1) was carried out by the quantification of protein abundance according to two clusters divergent for marbling (sub dataset 1). The verification step (2) was done by analysing the ability of one protein abundance to predict marbling values (linear regression) or classes (logistic regression) on all of the 43 samples. Protein abundances were evaluated by Parallel Reaction Monitoring (PRM) and Reverse Phase Protein Array (RPPA). *** $\mathrm{P}<0.001, * * \mathrm{P}<0.01, * \mathrm{P}<0.05,0.05$ $<t<0.15$.

Figure 2. Shear force and protein abundances in longissimus thoracis (LT) or semimembranosus (SM) muscles. The qualification step (1) was carried out by the quantification of protein abundance according to two clusters divergent for tenderness in LT (sub dataset 2) and in SM (sub data 3). The verification step (2) was done by analysing the ability of one protein abundance to predict tenderness values (linear regression) or classes (logistic regression) on all of the 43 samples. Protein abundances were evaluated by Parallel Reaction Monitoring (PRM) and Reverse Phase Protein Array (RPPA). *** $\mathrm{P}<0.001, * * \mathrm{P}<$ $0.01, * \mathrm{P}<0.05,0.05<t<0.15$. 
Marbling : 23 semimembranosus (SM) and 20 longissimus thoracis (LT) muscle from Rouge des Prés bovine

(1) Qualification

16 SM or LT muscles with the lowest $(n=8)$ or the highest $(n=8)$ marbling

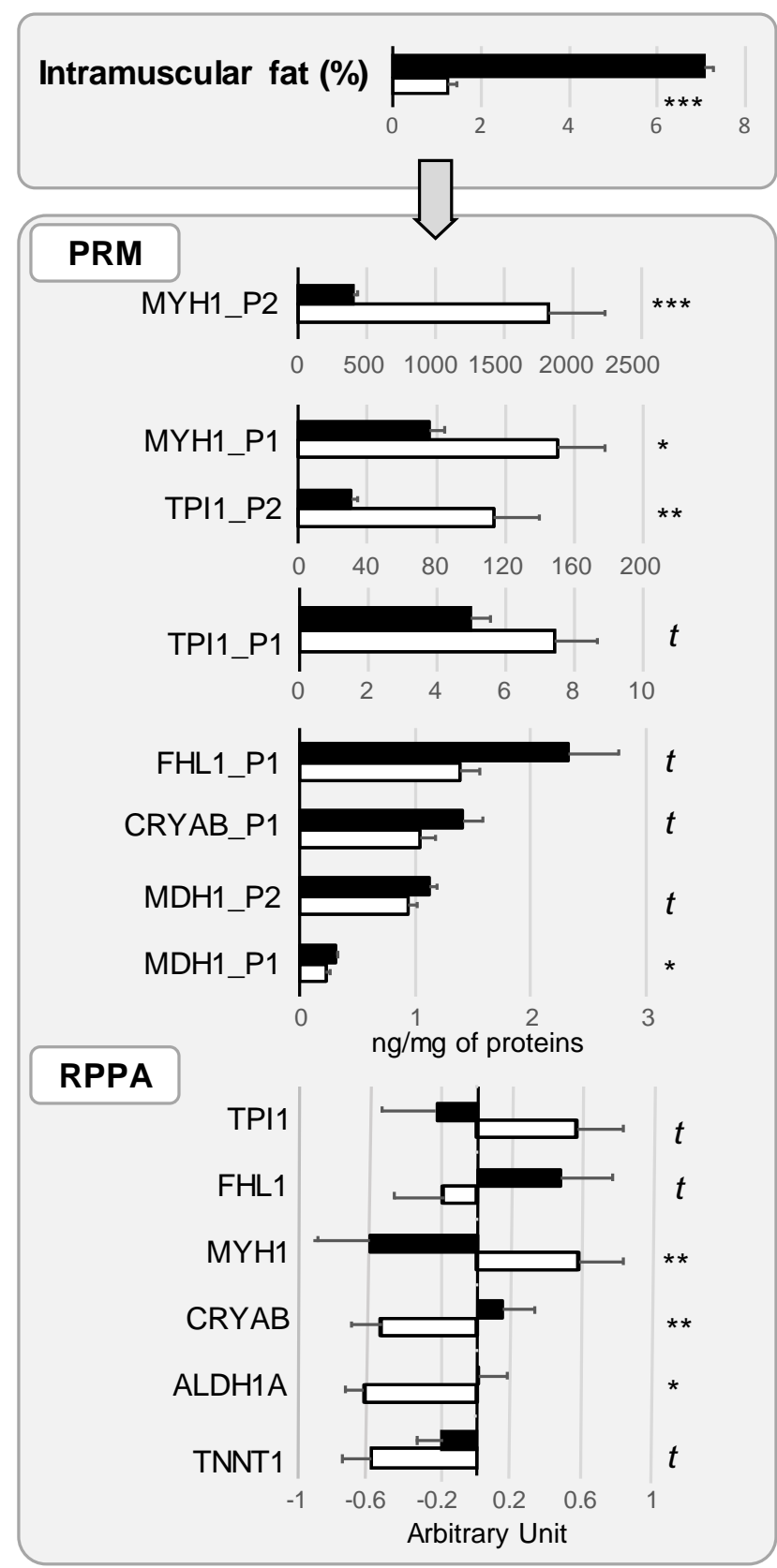

- High marbled $(\mathrm{n}=8) \quad$ Low marbled $(\mathrm{n}=8)$

\section{SM and LT muscles :}

a) covering the biological variation of marbling from 0.45 to $8.38 \%$ of lipid in fresh muscle (linear regression) or,

b) categorized in lean $(n=21$, $2.39 \pm 0.94 \%)$ and fat $(n=22$, $6.08 \pm 1.02 \%$ ) groups (logistic regression)

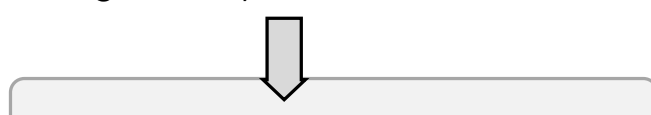

MYH1, TPI1, ALDH1A1, CRYAB verified as biomarkers of marbling

The abundance of one protein explains high part of marbling variability (Tables 3 and 4) 
Tenderness : 23 semimembranosus (SM) and 20 longissimus thoracis (LT) muscle from Rouge des Prés bovine

\section{(1) Qualification on LT}

10 LT muscles with the lowest $(n=5)$ or the highest $(n=5)$ shear force values

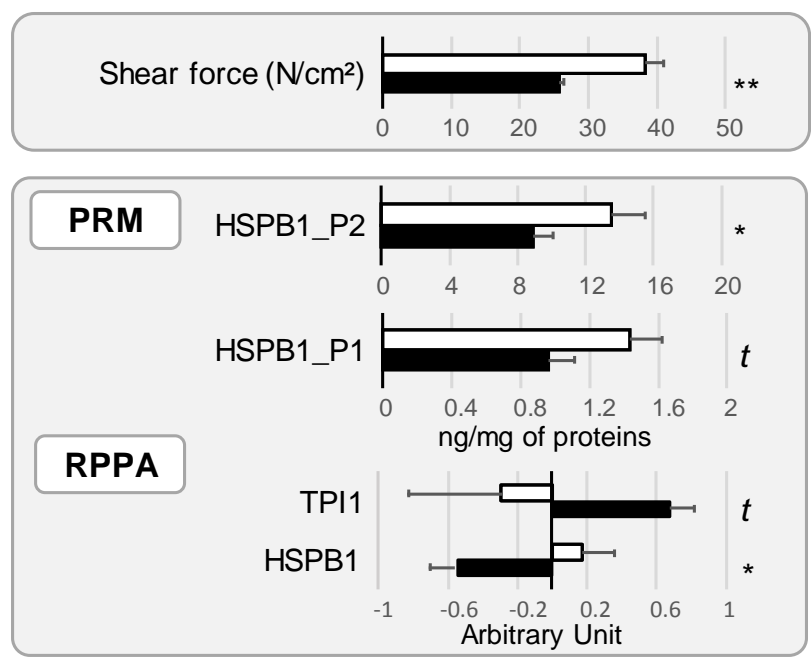

\section{(1) Qualification on SM}

10 SM muscles with the lowest $(n=5)$ or the highest $(n=5)$ shear force values
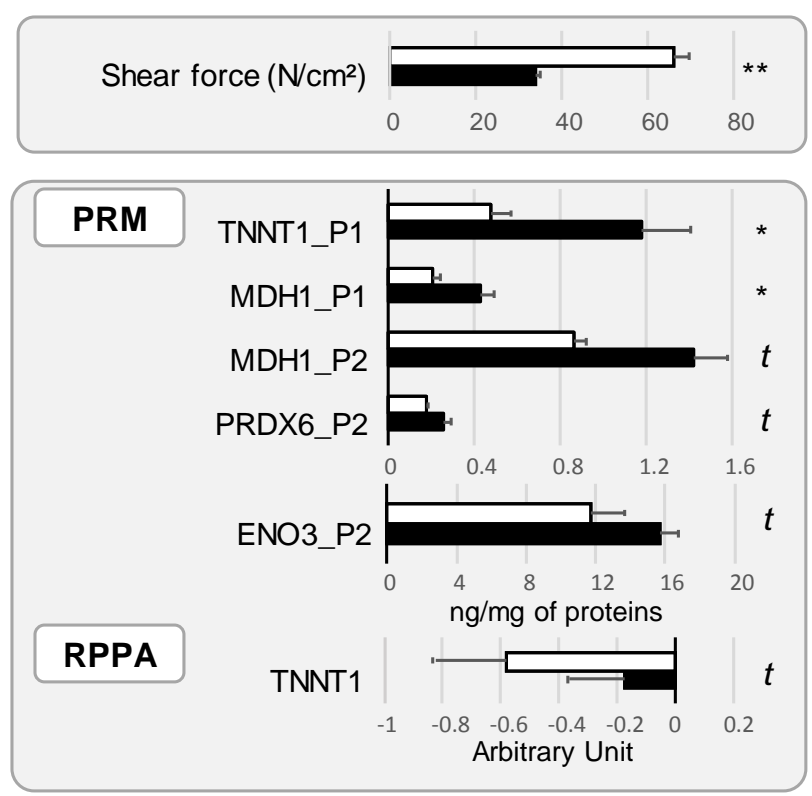

$\square$ Tough $(\mathrm{n}=5) \quad \boldsymbol{T}$ Tender $(\mathrm{n}=5)$

\section{Verification}

43 SM and LT muscles

a) covering the biological variation of tenderness from 23.63 to 76.91 $\mathrm{N} / \mathrm{cm}^{2}$ (linear regression) or,

b) categorized in tough $(\mathrm{n}=27$, $31.81 \pm 4.07 \mathrm{~N} / \mathrm{cm}^{2}$ ) and tender $\left(\mathrm{n}=16,54.17 \pm 10.22 \mathrm{~N} / \mathrm{cm}^{2}\right)$ groups (logistic regression)

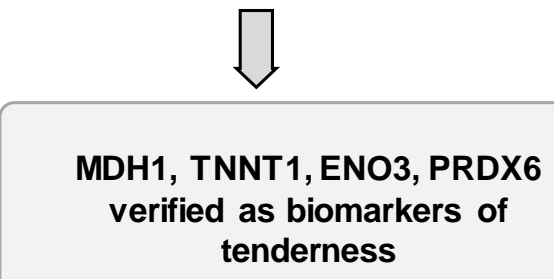

The abundance of one protein plus a muscle correction explain high part of tenderness variability (Table 3 ) 


\section{Table 1}

Limits of quantification of the LC-PRM assay established with accurately quantified stable isotope-labelled peptides.

\begin{tabular}{|c|c|c|c|c|c|c|c|c|c|c|c|}
\hline Protein Name & $\begin{array}{l}\text { Gene } \\
\text { Name }\end{array}$ & $\begin{array}{l}\text { Mass } \\
(\mathrm{kDa})\end{array}$ & Peptide Sequence & $\begin{array}{l}\text { Peptide } \\
\text { Name }\end{array}$ & LLOD (fmol) & 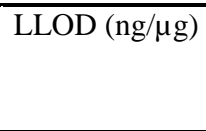 & LLOQ (fmol) & $\begin{array}{l}\text { ULOQ } \\
\text { (fmol) }\end{array}$ & $\begin{array}{l}\text { LLOQ } \\
(\mathrm{ng} / \mu \mathrm{g})\end{array}$ & $\begin{array}{l}\text { ULOQ } \\
(\mathrm{ng} / \mu \mathrm{g})\end{array}$ & $\begin{array}{l}\mathrm{CV} \text { at } \\
\mathrm{LLOQ} \\
(\%)\end{array}$ \\
\hline \multirow[t]{2}{*}{ sp|O77834|PRDX6_BOVIN } & PRDX6 & 25.07 & VIISLQLTAEK & $\begin{array}{l}\text { PRDX6_P1 } \\
\end{array}$ & 312.50 & 15.67 & NQ & NQ & NQ & NQ & NQ \\
\hline & & & LAPEFAK & PRDX6_P2 & 0.13 & 0.01 & 0.13 & 625 & 0.01 & 31.33 & 3.39 \\
\hline \multirow[t]{2}{*}{ sp|P02510|CRYAB_BOVIN } & CRYAB & 20.04 & HFSPEELK & CRYAB_P1 & 0.63 & 0.03 & 6.25 & 3125 & 0.25 & 125.20 & 2.58 \\
\hline & & & FSVNLDVK & CRYAB_P2 & 312.50 & 12.52 & 625.0 & 3125 & 25.05 & 125.20 & 7.24 \\
\hline \multirow[t]{2}{*}{ sp|P48644|AL1A1_BOVIN } & ALDH1A & 54.81 & QAFQIGSPWR & AL1A1_P1 & 3.13 & 0.34 & 3.13 & 312.5 & 0.34 & 34.25 & 1.71 \\
\hline & & & LECGGGPWGNK & AL1A1_P2 & 6.25 & 0.69 & 6.25 & 3125 & 0.69 & 342.54 & 2.05 \\
\hline \multirow[t]{2}{*}{ sp|Q3T145|MDHC_BOVIN } & MDH1 & 36.44 & VIVVGNPANTNCLTASK & MDHC_P1 & 0.31 & 0.02 & 0.31 & 1563 & 0.02 & 113.91 & 7.33 \\
\hline & & & LGVTSDDVK & MDHC_P2 & 3.13 & 0.23 & 3.13 & 1563 & 0.23 & 113.91 & 3.41 \\
\hline \multirow[t]{2}{*}{ sp|Q3T149|HSPB1_BOVIN } & HSPB 1 & 22.39 & ALPAAAIEGPAYNR & HSPB1_P1 & 0.63 & 0.03 & 0.63 & 3125 & 0.03 & 139.96 & 0.42 \\
\hline & & & SATQSAEITIPVTFQAR & HSPB1_P2 & 31.25 & 1.40 & 31.25 & 3125 & 1.40 & 1396.96 & 8.07 \\
\hline \multirow[t]{2}{*}{ sp|Q3ZC09|ENOB_BOVIN } & ENO3 & 47.10 & TAIQAAGYPDK & ENOB_P1 & 6.25 & 0.59 & 6.25 & 3125 & 0.59 & 294.35 & 0.91 \\
\hline & & & VNQIGSVTESIQACK & ENOB_P2 & 0.63 & 0.06 & 0.63 & 3125 & 0.06 & 294.35 & 8.67 \\
\hline \multirow[t]{2}{*}{ sp|Q5E956|TPIS_BOVIN } & TPI1 & 26.69 & VVLAYEPVWAIGTGK & TPIS_P1 & 31.25 & 0.17 & 31.25 & 3125 & 0.17 & 16.68 & 5.23 \\
\hline & & & NNLGELINTLNAAK & TPIS_P2 & 6.25 & 0.03 & 62.50 & 3125 & 0.33 & 16.68 & 19.90 \\
\hline \multirow[t]{2}{*}{ sp|Q8MKH6|TNNT1_BOVIN } & TNNT1 & 31.28 & YEINVLYNR & TNNT1_P1 & 3.13 & 0.20 & 3.12 & 1563 & 0.20 & 97.79 & 2.78 \\
\hline & & & AQELSDWIHQLESEK & TNNT1_P2 & 62.50 & 3.91 & 62.50 & 625 & 3.91 & 39.10 & 5.80 \\
\hline \multirow[t]{2}{*}{ sp|Q9BE40|MYH1_BOVIN } & MYH1 & 222.99 & TLALLFSGPASGEAEGGPK & MYH1_P1 & 6.25 & 2.79 & 6.25 & 3125 & 2.79 & 1393.69 & 1.61 \\
\hline & & & GQTVEQVYNAVGALAK & MYH1_P2 & 312.50 & 139.37 & 625.0 & 3125 & 278.74 & 1393.69 & 4.22 \\
\hline \multirow[t]{2}{*}{ tr|F1MR86|F1MR86_BOVIN } & FHL1 & 37.96 & NPITGFGK & FHL1_P1 & 0.31 & 0.02 & 0.31 & 1563 & 0.02 & 118.67 & 8.09 \\
\hline & & & CLQPLASETFVAK & FHL1_P2 & 3.13 & 0.24 & 3.13 & 1563 & 0.24 & 118.67 & 10.00 \\
\hline
\end{tabular}

LLOD: lower limit of detection. LLOQ: Lower limit of quantification. ULOQ: Upper limit of quantification. NQ: Not quantifiable. 
Table 2

Limits of quantification of protein abundance measurements for each antibody by Reverse Phase Protein Array (RPPA), as determined on a pool of all samples that was printed in 10 serial dilutions $(6700-13 \mu \mathrm{g} / \mathrm{ml}$ of total protein).

\begin{tabular}{|c|c|c|c|c|c|c|}
\hline $\begin{array}{l}\text { Protein biomarkers } \\
\text { name (gene) }\end{array}$ & Uniprot ID & Monoclonal (Mo) or Polyclonal (Po) antibodies references & Antibody dilutions & $\begin{array}{l}\text { ULOQ }(\mu \mathrm{g} / \mathrm{ml} \text { of } \\
\text { total protein })\end{array}$ & $\begin{array}{l}\text { LLOQ }(\mu \mathrm{g} / \mathrm{ml} \\
\text { of total protein) }\end{array}$ & $\begin{array}{l}\text { LLOD }(\mu \mathrm{g} / \mathrm{ml} \\
\text { of total protein) }\end{array}$ \\
\hline ALDH 1A1 & $\mathrm{P} 48644$ & Po. anti-bovine Abcam ab23375 & $1 / 500$ & 3000 & 500 & 100 \\
\hline CRYAB & P02511 & Mo. anti-bovine Assay Designs SPA-222 & $1 / 1000$ & 3000 & 500 & 200 \\
\hline ENO3 & P13929 & Mo. anti-human Abnova Eno3 (M01), clone 5D1 & $1 / 30000$ & 2500 & 400 & 100 \\
\hline FHL1 & Q3T173 & Po. anti-human Sigma AV34378 & $1 / 5000$ & 3500 & 400 & 50 \\
\hline HSPB1 & P04792 & Mo. anti-human Santa Cruz HSP27 (F-4):SC13132 & $1 / 3000$ & 3000 & 400 & 100 \\
\hline MDH1 & P40925 & Mo. anti-pig Rockland 100-601-145 & $1 / 1000$ & 3000 & 400 & 100 \\
\hline MYH1 & P12882 & Mo anti-bovine Biocytex 8F4 & $1 / 500$ & 3000 & 600 & 200 \\
\hline PRDX6 & P30041 & Mo. anti-human Abnova PRDX6 (M01), clone 3A10-2A11 & $1 / 500$ & 3000 & 600 & 100 \\
\hline TNNT1 & Q8MKH6 & Po. anti-human Sigma SAB2102501 & $1 / 4000$ & 3000 & 600 & 200 \\
\hline TPI 1 & Q5E956 & Po. anti-human Novus NBP1-31470 & $1 / 50000$ & 2500 & 500 & 400 \\
\hline
\end{tabular}
saturation of the signal. 


\section{Table 3}

Equation and performances for the linear predictive models of tenderness and marbling using the abundance of one protein, plus a muscle effect in the case of tenderness.

\begin{tabular}{|c|c|c|c|c|c|c|c|c|c|}
\hline \multirow{2}{*}{ Item } & \multirow{2}{*}{ Protein used } & \multirow{2}{*}{$\begin{array}{l}\text { Protein } \\
\text { abundance } \\
\text { method }\end{array}$} & \multirow{2}{*}{$\begin{array}{l}\mathrm{N} \text { of significant models } \\
\text { over } 500 \text { bootstraps }\end{array}$} & \multirow{2}{*}{\multicolumn{2}{|c|}{ Model equation }} & \multicolumn{2}{|l|}{$\mathrm{R}^{2}$} & \multicolumn{2}{|l|}{ MPE } \\
\hline & & & & & & Mean & CI & Mean & $\mathrm{CI}$ \\
\hline \multicolumn{10}{|c|}{ Shear force } \\
\hline (1) & MDH1_P1 & PRM & 445 & $\begin{array}{l}\text { LT } \\
\text { SM }\end{array}$ & $\begin{array}{l}43.66( \pm 3.44)-47.13( \pm 12.31) \mathrm{MDH} 1 \_\mathrm{P} 1 \\
43.66( \pm 3.44)-47.13( \pm 12.31) \mathrm{MDH} 1 \_\mathrm{P} 1+21.37( \pm 3.10) \mathrm{SM}\end{array}$ & 0.50 & {$[0.24 ; 0.65]$} & 0.23 & {$[0.18 ; 0.30]$} \\
\hline (2) & MDH1_P2 & PRM & 409 & $\begin{array}{l}\text { LT } \\
\text { SM }\end{array}$ & $\begin{array}{l}49.44( \pm 5.34)-18.56( \pm 5.24) \mathrm{MDH} 1 \_\mathrm{P} 2 \\
49.44( \pm 5.34)-18.56( \pm 5.24) \mathrm{MDH} 1 \_\mathrm{P} 2+21.87( \pm 3.20) \mathrm{SM}\end{array}$ & 0.48 & {$[0.22 ; 0.59]$} & 0.24 & {$[0.18 ; 0.31]$} \\
\hline (3) & TNNT1_P1 & PRM & 343 & $\begin{array}{l}\text { LT } \\
\text { SM }\end{array}$ & $\begin{array}{l}42.69( \pm 3.94)-13.41( \pm 4.46) \text { TNNT1_P1 } \\
42.69( \pm 3.94)-13.41( \pm 4.46) \text { TNNT1_P1 }+16.61( \pm 2.71) \mathrm{SM}\end{array}$ & 0.40 & {$[0.16 ; 0.48]$} & 0.26 & {$[0.19 ; 0.33]$} \\
\hline (4) & ENO3_P2 & PRM & 335 & $\begin{array}{l}\text { LT } \\
\text { SM }\end{array}$ & $\begin{array}{l}51.49( \pm 6.19)-1.57( \pm 0.46) \text { ENO3_P2 } \\
51.49( \pm 6.19)-1.57( \pm 0.46) \text { ENO3_P2 }+20.52( \pm 2.78) \mathrm{SM}\end{array}$ & 0.41 & {$[0.09 ; 0.49]$} & 0.25 & {$[0.19 ; 0.33]$} \\
\hline (5) & PRDX6_P2 & PRM & 305 & $\begin{array}{l}\text { LT } \\
\text { SM }\end{array}$ & $\begin{array}{l}48.05( \pm 3.90)-87.47( \pm 20.00) \text { PRDX6_P2 } \\
48.05( \pm 3.90)-87.47( \pm 20.00) \text { PRDX6_P2 }+19.78( \pm 2.99) \mathrm{SM}\end{array}$ & 0.42 & {$[0.23 ; 0,46]$} & 0.26 & {$[0.19 ; 0.33]$} \\
\hline \multicolumn{10}{|c|}{${ }^{2}$} \\
\hline (7) & ALDH1A & RPPA & 427 & LT and SM & $4.90( \pm 0.33)+2.27( \pm 0.49)$ ALDH1A & 0.18 & {$[0.02 ; 0.32]$} & 0.48 & $\begin{array}{l}{[0.35 ; 0.59]} \\
{[0.37 ; 0.62]}\end{array}$ \\
\hline (8) & MYH1_P2 & PRM & 413 & LT and SM & $5.46( \pm 0.42)-0.001( \pm 0.0003)$ MYH1_P2 & 0.19 & {$[0.005 ; 0.36]$} & 0.49 & {$[0.37 ; 0.66]$} \\
\hline (9) & TPI1_P2 & PRM & 434 & LT and SM & $5.44( \pm 0.41)-0.02( \pm 0.004)$ TPI1_P2 & 0.18 & {$[0.01 ; 0.34]$} & 0.48 & {$[0.37 ; 0.64]$} \\
\hline (10) & MYH1 & RPPA & 351 & LT and SM & $4.15( \pm 0.29)-1.16( \pm 0.28) \mathrm{MYH} 1$ & 0.12 & {$[0.005 ; 0.22]$} & 0.49 & {$[0.39 ; 0.62]$} \\
\hline (11) & CRYAB & RPPA & 334 & LT and SM & $4.57( \pm 0.30)+1.60( \pm 0.37) \mathrm{CRYAB}$ & 0.11 & {$[0.004 ; 0.17]$} & 0.50 & {$[0.39 ; 0.66]$} \\
\hline
\end{tabular}

The unit of protein abundances within the equation were ng/ $\mu \mathrm{g}$ of muscular protein when assayed by Parallel Reaction Monitoring (PRM) and Arbitrary Unit

when assayed by Reverse Phase Protein Array (RPPA).

LT: longissimus thoracis muscle; SM: semimembranosus muscle; MPE: mean prediction error; CI: confidence interval. 


\section{Table 4}

Equations and performances for the logistic predictive models of marbling using the abundance of one protein assayed by PRM (ng/ug of muscular protein)

\begin{tabular}{|c|c|c|c|c|c|c|c|c|c|c|c|}
\hline \multirow{2}{*}{ Item } & \multirow{2}{*}{ Protein used } & \multirow{2}{*}{$\begin{array}{l}\text { Protein } \\
\text { abundance } \\
\text { method }\end{array}$} & \multirow{2}{*}{$\begin{array}{l}\mathrm{N} \text { of significant } \\
\text { model over } 500 \\
\text { bootstraps }\end{array}$} & \multirow{2}{*}{ Model equation after the bootstrap } & \multirow{2}{*}{$\begin{array}{l}\text { Success rate } \\
(\%)\end{array}$} & \multicolumn{2}{|l|}{ AUC } & \multicolumn{2}{|l|}{ Accuracy $(\%)$} & \multicolumn{2}{|c|}{ Sensitivity $(\%)$} \\
\hline & & & & & & Mean & $\mathrm{CI}$ & Lean cluster & Fat cluster & Lean cluster & Fat cluster \\
\hline \multicolumn{12}{|c|}{ Intramuscular fat } \\
\hline (12) & TPI1_P2 & PRM & 322 & $-1.79( \pm 1.48)+0.003( \pm 0.003)$ TPI1_P2 & 61 & 0.75 & {$[0.57 ; 0.91]$} & 69 & 58 & 49 & 77 \\
\hline (13) & MYH1_P1 & PRM & 304 & $-2.77( \pm 0.97)+0.003( \pm 0.009)$ MYH1_P1 & 63 & 0.62 & {$[0.43 ; 0.79]$} & 65 & 56 & 58 & 65 \\
\hline (14) & MYH1_P2 & PRM & 313 & $-1.58( \pm 0.84)+0.001( \pm 0.001)$ MYH1_P2 & 61 & 0.72 & {$[0.54 ; 0.89]$} & 64 & 62 & 67 & 60 \\
\hline
\end{tabular}

AUC: area under the curve; CI: confidence interval. 


\section{Appendix A.}

\section{Supplemental Table 1}

Trait descriptions and protein abundances assayed by Parallel Reaction Monitoring (PRM) and Reverse Phase Protein Array (RPPA) for the 43

samples composed of longissimus thoracis (LT) and semimembranosus (SM) muscles.

\begin{tabular}{|c|c|c|c|c|c|c|c|c|c|}
\hline \multirow[t]{3}{*}{ Item } & \multicolumn{8}{|l|}{ Muscle } & \multirow{3}{*}{$P$} \\
\hline & \multicolumn{4}{|c|}{ SM $(n=23)$} & \multicolumn{4}{|c|}{$\mathrm{LT}(\mathrm{n}=20)$} & \\
\hline & Mean & SD & Min & $\operatorname{Max}$ & Mean & SD & Min & $\operatorname{Max}$ & \\
\hline \multicolumn{10}{|l|}{ Muscle traits } \\
\hline Shear force $\left(\mathrm{N} / \mathrm{cm}^{2}\right)$ & 47.73 & 12.75 & 30.32 & 76.91 & 31.40 & 5.56 & 23.63 & 47.46 & $<0.001$ \\
\hline Intramuscular fat (\%) & 4.02 & 2.19 & 0.98 & 8.39 & 4.39 & 2.02 & 0.45 & 7.48 & 0.44 \\
\hline \multicolumn{10}{|l|}{ Protein abundances } \\
\hline \multicolumn{10}{|c|}{ 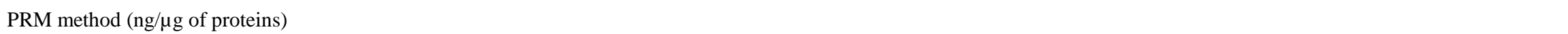 } \\
\hline CRYAB_P1 & 1.06 & 0.38 & 0.39 & 1.62 & 1.22 & 0.46 & 0.60 & 2.05 & 0.38 \\
\hline CRYAB_P2 & 42.70 & 16.75 & 16.69 & 80.72 & 42.02 & 17.53 & 13.80 & 74.18 & 0.95 \\
\hline ENO3_P1 & 36.34 & 7.31 & 23.24 & 55.34 & 33.86 & 7.31 & 16.08 & 50.64 & 0.30 \\
\hline ENO3_P2 & 15.35 & 3.53 & 7.26 & 24.34 & 12.71 & 2.74 & 5.64 & 16.37 & 0.002 \\
\hline FHL1_P1 & 1.56 & 0.65 & 0.59 & 3.05 & 2.20 & 0.81 & 0.67 & 3.88 & 0.01 \\
\hline FHL1_P2 & 4.03 & 1.81 & 1.69 & 7.77 & 5.14 & 2.15 & 1.03 & 10.52 & 0.06 \\
\hline HSPB1_P1 & 0.97 & 0.29 & 0.47 & 1.58 & 1.34 & 0.38 & 0.65 & 2.13 & 0.95 \\
\hline HSPB1_P2 & 10.24 & 3.48 & 4.68 & 18.54 & 12.05 & 4.65 & 5.79 & 24.32 & 0.24 \\
\hline MDH1_P1 & 0.36 & 0.14 & 0.12 & 0.55 & 0.26 & 0.08 & 0.09 & 0.43 & 0.01 \\
\hline MDH1_P2 & 1.25 & 0.33 & 0.74 & 1.72 & 0.97 & 0.20 & 0.63 & 1.40 & 0.01 \\
\hline MYH1_P1 & 113.27 & 43.97 & 60.25 & 252.54 & 90.76 & 52.51 & 10.35 & 261.51 & 0.03 \\
\hline MYH1_P2 & 1516.60 & 1078.53 & 359.30 & 4302.60 & 895.80 & 719.84 & 128.60 & 2456.30 & 0.03 \\
\hline PRDX6_P2 & 0.22 & 0.05 & 0.15 & 0.32 & 0.19 & 0.04 & 0.11 & 0.26 & 0.16 \\
\hline TNNT1_P1 & 0.85 & 0.47 & 0.22 & 2.04 & 0.84 & 0.22 & 0.48 & 1.27 & 0.54 \\
\hline TPI1_P1 & 7.79 & 3.49 & 1.67 & 18.29 & 5.93 & 2.69 & 1.41 & 13.63 & 0.03 \\
\hline TPI1_P2 & 97.24 & 68.92 & 20.79 & 252.34 & 60.99 & 49.63 & 22.05 & 193.56 & 0.03 \\
\hline
\end{tabular}




\begin{tabular}{|c|c|c|c|c|c|c|c|c|c|}
\hline ALDH1A & -0.38 & 0.37 & -1.00 & 0.40 & -0.22 & 0.48 & -0.88 & 0.66 & 0.37 \\
\hline CRYAB & -0.35 & 0.53 & -1.31 & 0.96 & -0.15 & 0.56 & -1.11 & 0.77 & 0.26 \\
\hline ENO3 & 0.48 & 0.58 & -0.35 & 2.05 & 0.23 & 0.75 & -1.65 & 1.20 & 0.48 \\
\hline FHL1 & 0.003 & 0.83 & -2.05 & 1.63 & 0.15 & 0.69 & -0.67 & 1.69 & 0.55 \\
\hline HSPB1 & -0.41 & 0.48 & -1.10 & 0.64 & -0.18 & 0.57 & -1.23 & 1.01 & 0.16 \\
\hline MDH1 & -0.10 & 0.45 & -1.05 & 0.64 & 0.10 & 0.35 & -0.50 & 0.86 & 0.14 \\
\hline MYH1 & 0.15 & 0.61 & -0.68 & 1.72 & -0.20 & 0.92 & -2.43 & 1.69 & 0.32 \\
\hline PRDX6 & 0.25 & 0.54 & -1.40 & 1.02 & -0.18 & 0.50 & -1.34 & 0.48 & 0.003 \\
\hline TNNT1 & -0.27 & 0.45 & -1.42 & 0.59 & -0.09 & 0.41 & -0.82 & 0.83 & 0.32 \\
\hline TPI1 & 0.47 & 0.72 & -0.72 & 1.90 & 0.15 & 0.81 & -2.17 & 1.00 & 0.26 \\
\hline
\end{tabular}

SD: Standard deviation. AU: Arbitrary Unit

The $\mathrm{p}$-values were obtained from a $\mathrm{X}$ test. 


\section{Supplemental Table 2}

Shear force, intramuscular fat content and protein abundances in longissimus thoracis (LT) or semimembranosus (SM) muscles according to two clusters divergent for marbling (dataset 1). Protein abundances were evaluated by Parallel Reaction Monitoring (PRM) and Reverse Phase Protein Array (RPPA).

\begin{tabular}{|c|c|c|c|c|c|c|c|c|c|}
\hline \multirow[t]{3}{*}{ Item } & \multicolumn{8}{|c|}{ Clusters of intramuscular fat } & \multirow{3}{*}{$\mathrm{P}$} \\
\hline & \multicolumn{4}{|c|}{ Lean $(\mathrm{n}=8)$} & \multicolumn{4}{|c|}{ Fat $(\mathrm{n}=8)$} & \\
\hline & Mean & SD & Min & Max & Mean & SD & Min & $\operatorname{Max}$ & \\
\hline \multicolumn{10}{|c|}{ Muscle traits (LT and SM) } \\
\hline Shear force $\left(\mathrm{N} / \mathrm{cm}^{2}\right)$ & 50.71 & 18.87 & 28.74 & 76.91 & 37.17 & 8.85 & 25.36 & 54.45 & 0.19 \\
\hline Intramuscular fat (\%) & 1.26 & 0.56 & 0.45 & 2.44 & 7.06 & 0.63 & 6.43 & 8.39 & $<0.001$ \\
\hline \multicolumn{10}{|c|}{ Protein abundances } \\
\hline \multicolumn{10}{|c|}{ PRM method (ng/ $\mu \mathrm{g}$ of proteins) } \\
\hline CRYAB_P1 & 1.04 & 0.37 & 0.57 & 1.54 & 1.41 & 0.48 & 0.80 & 2.05 & 0.13 \\
\hline CRYAB_P2 & 41.34 & 13.90 & 25.05 & 65.35 & 42.49 & 12.92 & 25.05 & 58.03 & 0.79 \\
\hline ENO3_P1 & 34.71 & 9.26 & 23.24 & 50.12 & 33.55 & 6.79 & 20.99 & 43.03 & 0.96 \\
\hline ENO3_P2 & 12.77 & 3.43 & 7.26 & 16.41 & 14.74 & 3.40 & 8.24 & 19.55 & 0.38 \\
\hline FHL1_P1 & 1.39 & 0.47 & 0.76 & 2.120 & 2.33 & 1.23 & 0.59 & 3.88 & 0.10 \\
\hline FHL1_P2 & 3.42 & 1.37 & 1.71 & 6.00 & 5.70 & 3.05 & 1.69 & 10.52 & 0.16 \\
\hline HSPB1_P1 & 0.99 & 0.34 & 0.63 & 1.58 & 1.27 & 0.45 & 0.73 & 2.13 & 0.16 \\
\hline HSPB1_P2 & 10.30 & 4.02 & 5.66 & 17.59 & 11.37 & 4.31 & 6.72 & 19.92 & 0.44 \\
\hline MDH1_P1 & 0.23 & 0.09 & 0.12 & 0.41 & 0.31 & 0.07 & 0.20 & 0.43 & 0.04 \\
\hline MDH1_P2 & 0.94 & 0.23 & 0.71 & 1.33 & 1.12 & 0.19 & 0.93 & 1.44 & 0.08 \\
\hline MYH1_P1 & 150.34 & 77.21 & 61.50 & 261.51 & 76.34 & 24.99 & 27.69 & 105.44 & 0.04 \\
\hline MYH1_P2 & 1818.20 & 1174.30 & 668.50 & 4302.60 & 396.90 & 87.72 & 278.70 & 516.20 & $<0.001$ \\
\hline PRDX6_P2 & 0.17 & 0.03 & 0.14 & 0.22 & 0.20 & 0.04 & 0.15 & 0.26 & 0.38 \\
\hline TNNT1_P1 & 0.57 & 0.23 & 0.22 & 0.92 & 0.77 & 0.27 & 0.40 & 1.24 & 0.23 \\
\hline TPI1_P1 & 7.42 & 3.55 & 1.67 & 12.44 & 4.97 & 1.59 & 1.67 & 6.77 & 0.11 \\
\hline TPI1_P2 & 113.71 & 72.95 & 29.66 & 245.06 & 30.62 & 9.77 & 20.79 & 51.19 & 0.003 \\
\hline \multicolumn{10}{|l|}{ RPPA method (AU) } \\
\hline ALDH1A & -0.63 & 0.30 & -0.97 & -0.11 & 0.005 & 0.46 & -0.59 & 0.56 & 0.02 \\
\hline CRYAB & -0.54 & 0.48 & -1.16 & 0.13 & 0.14 & 0.51 & -0.57 & 0.70 & 0.01 \\
\hline ENO3 & 0.47 & 0.69 & -0.09 & 2.05 & 0.16 & 0.88 & -1.65 & 1.36 & 0.80 \\
\hline
\end{tabular}




\begin{tabular}{|c|c|c|c|c|c|c|c|c|c|}
\hline FHL1 & -0.19 & 0.79 & -0.87 & 1.63 & 0.47 & 0.83 & -0.67 & 1.42 & 0.13 \\
\hline HSPB1 & -0.39 & 0.65 & -1.23 & 0.64 & -0.16 & 0.52 & -1.05 & 0.75 & 0.50 \\
\hline MDH1 & 0.01 & 0.40 & -0.51 & 0.44 & -0.20 & 0.50 & -1.05 & 0.59 & 0.38 \\
\hline MYH1 & 0.57 & 0.70 & -0.53 & 1.72 & -0.61 & 0.88 & -2.43 & 0.21 & 0.01 \\
\hline PRDX6 & -0.11 & 0.77 & -1.22 & 0.91 & -0.02 & 0.46 & -0.86 & 0.69 & 0.96 \\
\hline TNNT1 & -0.59 & 0.46 & -1.42 & -0.06 & -0.20 & 0.41 & -0.92 & 0.30 & 0.11 \\
\hline TPI1 & 0.56 & 0.75 & -0.45 & 1.90 & -0.23 & 0.89 & -2.17 & 0.56 & 0.08 \\
\hline
\end{tabular}

SD: Standard deviation.

The p-values were obtained from a Wilcoxon test. 


\section{Supplemental Table 3}

Shear force, intramuscular fat content and protein abundances in longissimus thoracis muscle (LT) and semimembranosus muscle (SM) according to two clusters divergent for tenderness (dataset 2 for LT and dataset 3 for SM). Protein abundances were evaluated by Parallel Reaction Monitoring (PRM) and Reverse Phase Protein Array (RPPA).

\begin{tabular}{|c|c|c|c|c|c|c|c|c|c|}
\hline \multirow{3}{*}{ Item } & \multicolumn{8}{|c|}{ Tenderness clusters } & \multirow{3}{*}{$P$} \\
\hline & \multicolumn{4}{|c|}{ Tender $(\mathrm{n}=5)$} & \multicolumn{4}{|c|}{ Tough $(\mathrm{n}=5)$} & \\
\hline & Mean & SD & Min & Max & Mean & SD & Min & Max & \\
\hline \multicolumn{10}{|l|}{ LT muscle traits } \\
\hline Shear force $\left(\mathrm{N} / \mathrm{cm}^{2}\right)$ & 25.79 & 1.61 & 23.63 & 27.77 & 38.17 & 6.19 & 33.40 & 47.46 & 0.008 \\
\hline Intramuscular fat (\%) & 5.636 & 0.95 & 4.76 & 7.07 & 4.64 & 2.28 & 2.930 & 7.48 & 0.53 \\
\hline \multicolumn{10}{|c|}{ Protein abundances } \\
\hline \multicolumn{10}{|c|}{ PRM method (ng/mg of proteins) } \\
\hline CRYAB_P1 & 1.00 & 0.55 & 0.61 & 1.95 & 1.39 & 0.63 & 0.60 & 2.05 & 0.55 \\
\hline CRYAB_P2 & 32.30 & 15.45 & 18.52 & 58.03 & 41.87 & 23.30 & 13.80 & 74.18 & 0.55 \\
\hline ENO3_P1 & 33.67 & 2.33 & 32.25 & 37.80 & 36.47 & 11.13 & 20.99 & 50.64 & 0.69 \\
\hline ENO3_P2 & 12.89 & 2.01 & 11.52 & 16.37 & 11.98 & 3.36 & 8.24 & 16.31 & 1 \\
\hline FHL1_P1 & 1.89 & 0.50 & 1.22 & 2.60 & 2.31 & 1.27 & 0.67 & 3.88 & 0.69 \\
\hline FHL1_P2 & 4.51 & 1.55 & 3.04 & 7.15 & 5.03 & 2.96 & 1.03 & 8.80 & 0.84 \\
\hline HSPB1_P1 & 0.96 & 0.35 & 0.65 & 1.55 & 1.43 & 0.42 & 1.04 & 2.13 & 0.09 \\
\hline HSPB1_P2 & 8.89 & 2.66 & 6.67 & 13.11 & 13.57 & 4.44 & 8.47 & 19.92 & 0.05 \\
\hline MDH1_P1 & 0.26 & 0.05 & 0.21 & 0.34 & 0.20 & 0.07 & 0.09 & 0.26 & 0.22 \\
\hline MDH1_P2 & 0.97 & 0.12 & 0.82 & 1.11 & 0.87 & 0.14 & 0.65 & 1.01 & 0.55 \\
\hline MYH1_P1 & 78.24 & 13.30 & 69.35 & 101.68 & 90.85 & 44.57 & 60.01 & 169.46 & 1 \\
\hline MYH1_P2 & 583.00 & 114.57 & 485.90 & 732.30 & 694.90 & 575.72 & 220.30 & 1686.70 & 0.42 \\
\hline PRDX6_P1 & 1.56 & 0.43 & 1.15 & 2.22 & 1.83 & 0.76 & 0.94 & 2.85 & 0.55 \\
\hline PRDX6_P2 & 0.20 & 0.02 & 0.17 & 0.23 & 0.18 & 0.06 & 0.11 & 0.26 & 0.55 \\
\hline TNNT1_P1 & 0.82 & 0.07 & 0.71 & 0.89 & 0.78 & 0.30 & 0.48 & 1.27 & 0.55 \\
\hline TPI1_P1 & 5.32 & 0.15 & 5.19 & 5.55 & 4.73 & 2.00 & 1.67 & 7.22 & 0.42 \\
\hline TPI1_P2 & 38.26 & 5.51 & 31.23 & 43.96 & 42.87 & 19.29 & 22.05 & 61.79 & 0.69 \\
\hline \multicolumn{10}{|l|}{ RPPA method (AU) } \\
\hline ALDH1A1 & -0.30 & 0.43 & -0.88 & 0.17 & -0.10 & 0.57 & -0.71 & 0.56 & 0.69 \\
\hline CRYAB & -0.51 & 0.37 & -0.91 & -0.12 & 0.17 & 0.73 & -0.75 & 0.77 & 0.22 \\
\hline ENO3 & 0.68 & 0.42 & 0.20 & 1.10 & -0.01 & 1.17 & -1.65 & 1.20 & 0.55 \\
\hline FHL1 & 0.06 & 0.64 & -0.67 & 0.88 & 0.51 & 0.94 & -0.46 & 1.69 & 0.69 \\
\hline HSPB1 & -0.54 & 0.34 & -0.94 & -0.11 & 0.17 & 0.42 & -0.23 & 0.75 & 0.02 \\
\hline MDH1 & -0.02 & 0.20 & -0.29 & 0.23 & 0.004 & 0.48 & -0.50 & 0.59 & 1 \\
\hline МyHC & -0.11 & 0.24 & -0.39 & 0.14 & -0.18 & 0.80 & -1.12 & 0.64 & 0.69 \\
\hline PRDX6 & 0.00 & 0.27 & -0.29 & 0.39 & -0.32 & 0.77 & -1.34 & 0.48 & 0.84 \\
\hline
\end{tabular}


TNNT

TPI

SM muscle traits

Shear force $\left(\mathrm{N} / \mathrm{cm}^{2}\right)$

Intramuscular fat (\%)

Protein abundances

PRM method (ng/mg of proteins)

$$
\text { CRYAB_P }
$$

CRYAB_P2

ENO3_P2

FHL1_P1

FHL1_P2

HSPB1_P1

HSPB1_P2

MDH1_P1

MDH1_P2

MYH1_P1

MYH1_P2

PRDX6_P1

PRDX6_P2

TNNT1_P1

TPI1_P1

RPPA method (AU)

ALDH1A1

CRYAB

ENO3

FHL1

HSPB 1

MDH1

$\mathrm{MyHC}$

PRDX6

TNNT

TPI $\begin{array}{ll}-0.07 & 0.28 \\ 0.68 & 0.31\end{array}$

0.31

$33.90 \quad 2.13$

$\begin{array}{ll}33.90 & 2.13 \\ 3.17 & 1.49\end{array}$

1.20

$34.72-4.65$

$\begin{array}{ll}15.68 & 2.30\end{array}$

$1.76 \quad 0.52$

$\begin{array}{ll}4.57 & 1.50\end{array}$

$9.44 \quad 2.35$

$0.43 \quad 0.14$

$\begin{array}{ll}1.42 & 0.36\end{array}$

$115.75 \quad 38.87$

$\begin{array}{ll}1070.10 & 361.52 \\ 2.79 & 0.60\end{array}$

$\begin{array}{ll}0.26 & 0.07\end{array}$

$1.18 \quad 0.51$

$6.28 \quad 1.01$

$-0.39 \quad 0.54$

$\begin{array}{ll}-0.24 & 0.73\end{array}$

$0.156 \quad 0.41$

$\begin{array}{ll}-0.27 & 1.18\end{array}$

$\begin{array}{ll}-0.65 & 0.39 \\ -0.21 & 0.30 \\ 0.16 & 0.92\end{array}$

$0.16 \quad 0.92$

$0.26 \quad 0.39$

$-0.17 \quad 0.43$

\begin{tabular}{ll}
0.17 & 0.43 \\
0.23 & 0.62 \\
\hline
\end{tabular}

SD: Standard deviation.

\begin{tabular}{|c|c|c|c|c|c|c|}
\hline-0.54 & 0.20 & -0.11 & 0.48 & -0.68 & 0.370 & 1 \\
\hline 0.28 & 1.00 & -0.30 & 1.22 & -2.17 & 0.93 & 0.12 \\
\hline 30.32 & 35.46 & 66.24 & 7.47 & 58.93 & 76.91 & 0.008 \\
\hline 1.28 & 5.46 & 2.98 & 2.08 & 0.98 & 6.09 & 0.84 \\
\hline 0.65 & 1.61 & 0.915 & 0.54 & 0.39 & 1.54 & 0.31 \\
\hline 21.84 & 52.33 & 34.49 & 14.35 & 18.40 & 52.51 & 0.69 \\
\hline 26.72 & 37.86 & 31.60 & 7.44 & 23.24 & 42.77 & 0.42 \\
\hline 11.73 & 17.72 & 11.72 & 4.26 & 7.26 & 16.41 & 0.15 \\
\hline 1.15 & 2.31 & 1.23 & 0.37 & 0.84 & 1.65 & 0.22 \\
\hline 2.93 & 6.04 & 2.93 & 1.07 & 1.71 & 4.30 & 0.22 \\
\hline 0.63 & 1.22 & 0.91 & 0.46 & 0.47 & 1.58 & 0.55 \\
\hline 6.26 & 11.69 & 8.51 & 3.98 & 4.68 & 14.62 & 0.42 \\
\hline 0.19 & 0.55 & 0.21 & 0.07 & 0.12 & 0.28 & 0.05 \\
\hline 0.78 & 1.64 & 0.87 & 0.12 & 0.74 & 1.07 & 0.09 \\
\hline 80.27 & 172.48 & 124.96 & 76.86 & 61.50 & 252.54 & 0.84 \\
\hline 555.70 & 1517.20 & 1290.80 & 415.02 & 893.00 & 1794.40 & 0.69 \\
\hline 2.04 & 3.52 & 2.26 & 0.94 & 1.42 & 3.86 & 0.31 \\
\hline 0.16 & 0.32 & 0.18 & 0.02 & 0.15 & 0.20 & 0.09 \\
\hline 0.48 & 1.88 & 0.48 & 0.21 & 0.22 & 0.76 & 0.03 \\
\hline 4.91 & 7.30 & 5.32 & 2.32 & 1.67 & 7.70 & 0.69 \\
\hline 36.97 & 69.57 & 67.39 & 35.88 & 29.66 & 112.31 & 1 \\
\hline-0.99 & 0.40 & -0.73 & 0.30 & -1.00 & -0.39 & 0.22 \\
\hline-0.93 & 0.96 & -0.59 & 0.57 & -1.31 & 0.13 & 0.55 \\
\hline-0.35 & 0.73 & 0.49 & 0.62 & -0.09 & 1.19 & 0.60 \\
\hline-2.05 & 1.10 & -0.55 & 0.34 & -0.87 & -0.03 & 0.55 \\
\hline-1.10 & -0.21 & -0.30 & 0.60 & -0.92 & 0.64 & 0.55 \\
\hline-0.48 & 0.29 & 0.14 & 0.35 & -0.41 & 0.44 & 0.22 \\
\hline-0.68 & 1.72 & 0.66 & 0.50 & -0.06 & 1.14 & 0.21 \\
\hline-0.40 & 0.65 & 0.16 & 0.66 & -0.79 & 1.02 & 0.84 \\
\hline-0.92 & 0.10 & -0.58 & 0.55 & -1.42 & -0.02 & 0.15 \\
\hline-0.72 & 0.72 & 0.57 & 0.66 & -0.45 & 1.27 & 0.31 \\
\hline
\end{tabular}

0.55
0.66

0.15
0.31

The p-values were obtained from a Wilcoxon test. 
Ceciliani, F., Lecchi, C., Bazile, J., \& Bonnet, M. (2018). Proteomics Research in the Adipose Tissue. In A. M. de Almeida, D. Eckersall \& I. Miller (Eds.), Proteomics in Domestic Animals: from Farm to Systems Biology (pp. 233-254). Cham: Springer International Publishing.

Picard, B., Gagaoua, M., \& Hollung, K. (2017). Chapter 12 Gene and Protein Expression as a Tool to Explain/Predict Meat (and Fish) Quality. In New Aspects of Meat Quality (pp. 321-354).

Wu, W., Dai, R.-T., \& Bendixen, E. (2019). Comparing SRM and SWATH Methods for Quantitation of Bovine Muscle Proteomes. Journal of Agricultural and Food Chemistry, 67(5), 1608-1618. https://doi.org/10.1021/acs.jafc.8b05459. 